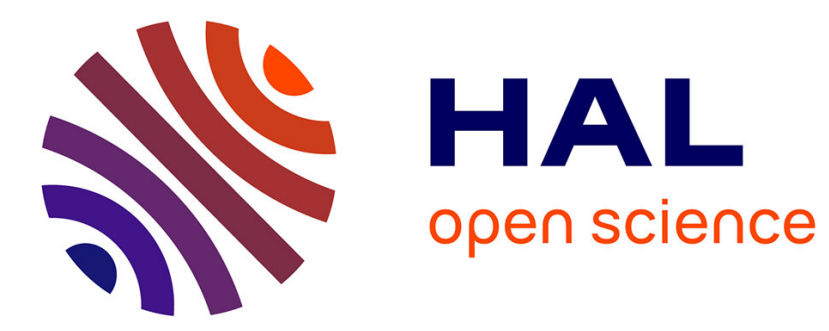

\title{
Tunable Degradation of Copolymers Prepared by Nitroxide-Mediated Radical Ring-Opening Polymerization and Point-by-Point Comparison with Traditional Polyesters
}

Elise Guegain, Jean-Philippe Michel, Tanguy Boissenot, Julien Nicolas

\section{To cite this version:}

Elise Guegain, Jean-Philippe Michel, Tanguy Boissenot, Julien Nicolas. Tunable Degradation of Copolymers Prepared by Nitroxide-Mediated Radical Ring-Opening Polymerization and Pointby-Point Comparison with Traditional Polyesters. Macromolecules, 2018, 51 (3), pp.724-736. 10.1021/acs.macromol.7b02655 . hal-02323684

\section{HAL Id: hal-02323684 \\ https://hal.science/hal-02323684}

Submitted on 21 Oct 2019

HAL is a multi-disciplinary open access archive for the deposit and dissemination of scientific research documents, whether they are published or not. The documents may come from teaching and research institutions in France or abroad, or from public or private research centers.
L'archive ouverte pluridisciplinaire HAL, est destinée au dépôt et à la diffusion de documents scientifiques de niveau recherche, publiés ou non, émanant des établissements d'enseignement et de recherche français ou étrangers, des laboratoires publics ou privés. 


\title{
Tunable Degradation of Copolymers Prepared by
}

\author{
Nitroxide-Mediated Radical Ring-Opening \\ Polymerization and Point-by-Point Comparison \\ with Traditional Polyesters
}

Elise Guégain, ${ }^{1}$ Jean-Philippe Michel, ${ }^{1}$ Tanguy Boissenot, ${ }^{1}$ Julien Nicolas ${ }^{1, *}$

\footnotetext{
${ }^{1}$ Institut Galien Paris-Sud, UMR CNRS 8612, Univ Paris-Sud, Faculté de Pharmacie, 5 rue Jean-Baptiste Clément, F-92296 Châtenay-Malabry cedex, France.
}

*To whom correspondence should be addressed.

Email: julien.nicolas@u-psud.fr

Twitter : @ julnicolas

Tel.: +33146835853 


\begin{abstract}
Two libraries of well-defined, degradable vinyl copolymers of opposite solubility, based either on methyl methacrylate (MMA) or on oligo(ethylene glycol) methyl ether methacrylate (OEGMA), and containing various amount of 2-methylene-4-phenyl-1,3-dioxolane (MPDL), were synthesized by nitroxide-mediated radical ring-opening polymerization. A comprehensive degradation study (long-term hydrolytic degradation, degradation of thick and thin films, water uptake, enzymatic degradation) was then performed and results were compared with those from traditional aliphatic polyesters (PLGA, PLA and PCL). It appeared that P(MMA-co-MPDL) copolymers slowly degraded in PBS with degradation kinetics slower than that of PCL whereas P(OEGMA-co-MPDL) copolymers led to significant degradation, in between that of PLA and PCL, depending on the amount of MPDL, but without leading to a dramatic drop of $\mathrm{pH}$ as for PLGA and PLA. Whereas P(MMA-coMPDL) copolymers might be well-suited for biomaterials intended for long-term use (e.g., devices, implants), faster degrading P(OEGMA-co-MPDL) copolymers might be envisioned for short- or mid-term applications such as nanoscale drug-delivery systems and meet a need for hydrophilic degradable materials with tunable degradation kinetics.
\end{abstract}




\section{Table of Content Graphic}

Tunable Degradation of Copolymers Prepared by Nitroxide-Mediated Radical Ring-Opening Polymerization and Point-by-Point Comparison with Traditional Polyesters

Elise Guégain, Jean-Philippe Michel, Tanguy Boissenot, Julien Nicolas*
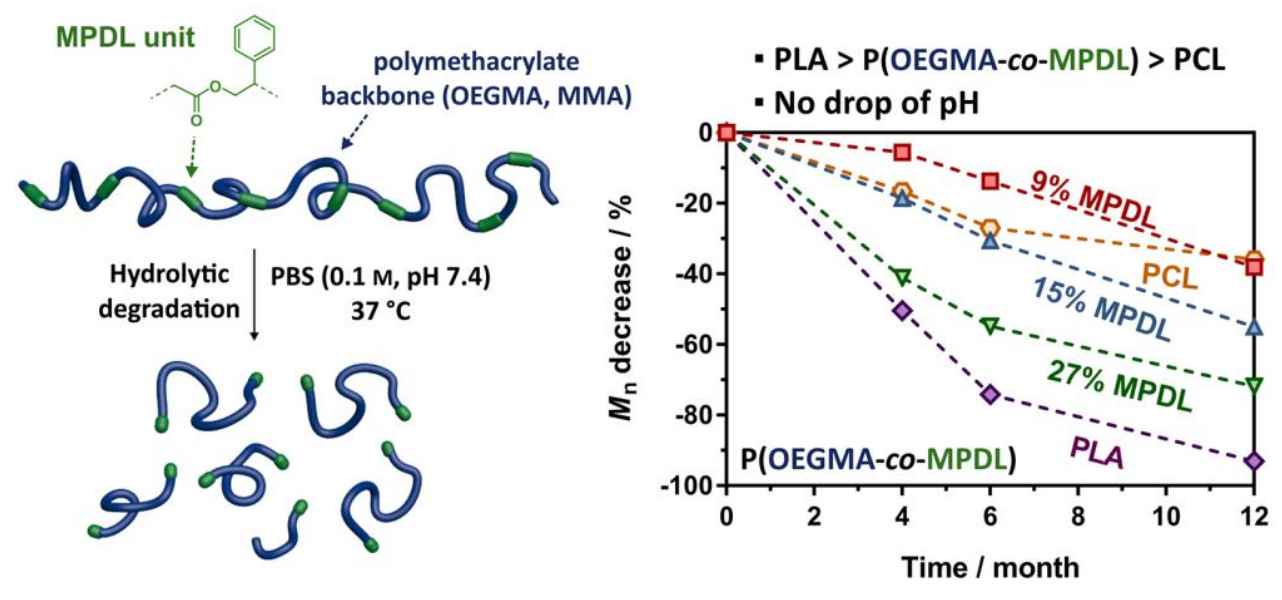


\section{Introduction}

The development of (bio)degradable polymers is currently the focus of great attention given their use in a wide range of applications including (nano)medicine, microelectronics and environmental protection. ${ }^{1-3}$ Polymers intended for biomedical applications are indeed of extreme importance for drug delivery or tissue engineering applications and should usually meet the following criteria: (i) biodegradability (mainly for administered materials) and biocompatibility (to avoid toxic side-effects); (ii) uniformity in polymer chain length and composition to ensure a reproducible biological response and (iii) functionalizability with biologically active (macro)molecules (e.g., drugs, targeting ligands) and fluorescent probes for therapeutic and diagnostic/tracing purposes, respectively.

Among the different classes of biodegradable polymers, aliphatic polyesters synthesized by ring-opening polymerization (ROP) of cyclic monomers (e.g., lactide, glycolide, caprolactone, etc.) are certainly the most studied materials for biomedical applications, including the manufacture of resorbable sutures, tissue engineering scaffolds and drug delivery systems. ${ }^{4}$ Importantly, polycaprolactone (PCL), polylactide (PLA), polyglycolide (PGA) and poly(lactide-co-glycolide) (PLGA) have gained Food and Drug Administration (FDA) approval for use in humans as a result of their biocompatibility and biodegradability. ${ }^{5,6}$ Other degradable polymers rapidly emerged as promising candidates such as synthetic polypeptides, polyanhydrides, poly(alkyl cyanoacrylates), poly(ortho esters), polyamides, etc. ${ }^{7}$

Vinyl polymers are very attractive materials and present numerous benefits compared to traditional polyesters owing to their ease of synthesis and their broad diversity of architectures, compositions and functionalities. For instance, these features have enabled the design of highly sophisticated and innovative polymer-protein/peptide bioconjugates or nanocarriers for drug delivery. These achievements were made possible in particular since the 
advent of reversible deactivation radical polymerization (RDRP) techniques, such as nitroxide-mediated polymerization $(\mathrm{NMP}){ }^{8}$ atom-transfer radical polymerization (ATRP) ${ }^{9}$ and reversible addition-fragmentation chain transfer (RAFT) polymerization. ${ }^{10}$ However, given their carbon-carbon backbones, they are extremely resistant to degradation and this property strongly limits their application in the biomedical field because potential bioaccumulation in the organism may cause toxicity. This is unfortunate in regards to the massive amount of work devoted to vinyl polymer-based systems intended for biomedical applications.

This critical situation and the general need for more environmentally friendly plastic materials further stimulated the development of degradable vinyl polymers. ${ }^{11}$ Among the different strategies, radical ring-opening polymerization (rROP) represents one of the most promising approaches because it combines the advantages of a radical mechanism, thus being fully compatible with free-radical polymerization and RDRP methods, and it enables insertion of labile groups (e.g., ester, disulfide, etc.) in the polymer backbone to ensure degradation. ${ }^{12}$ Different classes of cyclic monomers undergoing a radical ring-opening mechanism have been developed and among them, cyclic ketene acetals (CKA), ${ }^{13,14}$ originally developed by Bailey in the 80 's, are perhaps the most used monomers for rROP. Interestingly, CKA can be copolymerized with certain traditional vinyl monomers, mainly (meth)acrylic esters and vinyl acetate, ${ }^{15-22}$ allowing for tunable insertion of ester groups in the resulting copolymers. For instance, a variety of different copolymers based on 2-methylene-1,3-dioxepane (MDO) or 5,6-benzo-2-methylene-1,3-dioxepane (BMDO), which represent the two main CKA used in the literature, have been reported for potential applications in drug delivery, tissue engineering, hydrophobic coatings, or as other kinds of structural biomaterials.

Recently, our group revisited the use of 2-methylene-4-phenyl-1,3-dioxolane (MPDL) by optimizing its synthesis ${ }^{23}$ and using it as a comonomer during the NMP of either 
$\mathrm{OEGMA}^{24}$ or $\mathrm{MMA}^{23}$ to make degradable PEG-based or PMMA-rich materials, respectively (Figure 1). Even though NMP of methacrylic esters is known to be relatively difficult to achieve, the styrene-like open radical structure of MPDL allowed good control and high living chain fractions to be achieved during its copolymerization with methacrylic esters by acting as a so-called 'controlling' comonomer. Conversely to the use of BMDO or MDO under identical experimental conditions, MPDL enabled high monomer conversions to be reached and tunable insertion in the copolymers, thus leading to adjustable degradation; from moderate to nearly complete. ${ }^{24}$ Also, neither the resulting P(OEGMA-co-MPDL) copolymers nor their degradation products were cytotoxic up to high concentration on three representative cell lines. ${ }^{24}$ As for P(MMA-co-MPDL) copolymers, insertion of MPDL only moderately affected the glass transition temperature compared to pure PMMA, while giving low molar mass degradation products after hydrolysis. ${ }^{23}$

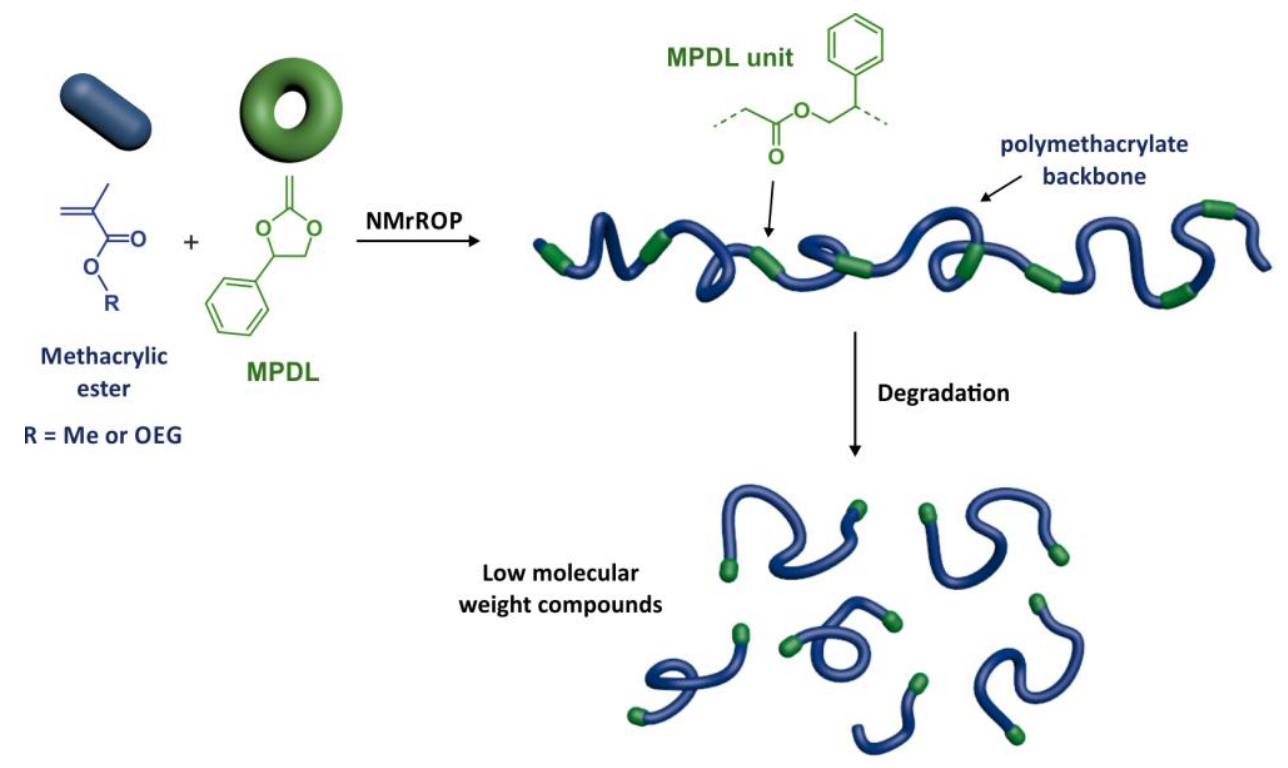

Figure 1. Synthesis of degradable copolymers by nitroxide-mediated radical ring-opening copolymerization (NMrROP) between methacrylic esters and 2-methylene-4-phenyl-1,3dioxolane (MPDL) as ester bound precursor in the copolymer backbone. 
In these studies, copolymer degradation was performed under accelerated conditions to probe the presence of open CKA units; in aqueous 5\% KOH for OEGMA-based copolymers and in THF/MeOH solution with 5\% KOH for MMA-based counterparts. Degradation kinetics were rapid (from minutes to hours) and allowed to confirm the presence of labile groups in the copolymer backbones. However, even though these harsh degradation conditions are usually used for such a purpose, they do not reflect the physiological conditions and are thus poorly predictive of the materials fate in a biological environment. Also, to the best of our knowledge, degradation of CKA-based materials under physiological conditions have never been benchmarked with traditional aliphatic polyesters such as PLGA, PLA and PCL, which still represent gold standards in terms of degradable polymers for biomedical applications. Only degradation in the presence of enzymes are sometimes reported. ${ }^{16,25-27}$ This missing information is crucial for designing the right materials having the degradation pattern that match with the target application.

Herein, we performed a comprehensive degradation study of two distinct libraries of CKA-containing copolymers, namely hydrophilic P(OEGMA-co-MPDL) and hydrophobic P(MMA-co-MPDL) (Figure 2), under conditions mimicking the physiological environment. In particular, we simultaneously investigated: (i) the long term hydrolytic degradation in PBS at different $\mathrm{pH}$; (ii) the physical erosion of thick and thin polymer films and (iii) the enzymatic degradation. A point-by-point comparison under identical conditions was also performed with the three representative aliphatic polyesters (i.e., PLGA, PLA and PCL, Figure 2), allowing the different materials to be compared and some preliminary structuredegradation relationships to be established. 


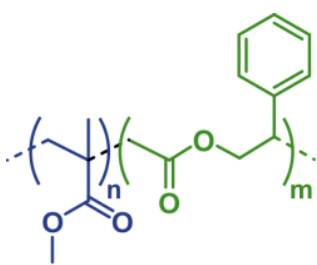

P(MMA-co-MPDL)<smiles>CCOC(C)C(=O)OC(C)C(C)=O</smiles>

PLA

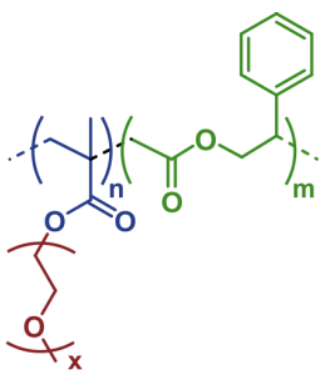

P(OEGMA-co-MPDL)<smiles>CC(=O)CCCCCOCC(C)C</smiles>

PCL<smiles>CC(=O)COC(=O)COC(C)(C)C(=O)C(C)OC(=O)C(C)OC(C)C</smiles>

PLGA

Figure 2. Chemical structure of the different polyesters employed in this study: poly[(methyl methacrylate)-co-(2-methylene-4-phenyl-1,3-dioxolane)]

(P(MMA-co-MPDL)), poly[(oligo(ethylene glycol) methyl ether methacrylate)-co-(2-methylene-4-phenyl-1,3dioxolane)] (P(OEGMA-co-MPDL)), poly(D,L-lactide-co-glycolide) (PLGA), poly(D,Llactide) (PLA) and polycaprolactone (PCL).

\section{Experimental part}

\section{Materials}

Oligo(ethylene glycol) methyl ether methacrylate (OEGMA, $\left.M_{\mathrm{n}}=300 \mathrm{~g} \cdot \mathrm{mol}^{-1}\right)$, styrene $(\mathrm{S}$, 99\%), methyl methacrylate (MMA, 99\%), anhydrous toluene (99.8\%), lipase B from Candida Antartica immobilized on immobead (4019 U/g) were purchased from Sigma-Aldrich and used as received (except for MMA which was distilled under reduced pressure). BlocBuilder $\mathrm{MA}^{\mathrm{TM}}$ alkoxyamine and the SG1 nitroxide were kindly provided by Arkema. Poly(D,Llactide-co-glycolide) (Resomer ${ }^{\circledR}$ RG 503, lactide:glycolide 50:50, ester terminated, $M_{\mathrm{w}}=24$ 000-38 000 g.mol $\left.{ }^{-1}\right)$, poly(D,L-lactide) $\left(\right.$ Resomer $^{\circledR}$ R 203 S, ester terminated, $M_{\mathrm{w}}=18000$ $28000 \mathrm{~g} \cdot \mathrm{mol}^{-1}$ ) and polycaprolactone (average $M_{\mathrm{n}}=45000 \mathrm{~g} \cdot \mathrm{mol}^{-1}$ ) were obtained from 
Sigma-Aldrich. 2-Methylene-4-phenyl-1,3-dioxolane (MPDL) monomer was prepared according to a previously published method (using the cyclic bromoacetal as an intermediate). ${ }^{23}$ All other materials were purchased from Sigma-Aldrich at the highest available purity and used as received. Phosphate buffer saline (PBS $0.1 \mathrm{M}$, with $0.9 \% \mathrm{NaCl}$ and $\left.0.02 \% \mathrm{NaN}_{3}, \mathrm{pH} 7.4\right)$ and acetate buffer $\left(0.1 \mathrm{M}\right.$, with $\left.0.02 \% \mathrm{NaN}_{3}, \mathrm{pH} 5.5\right)$ were prepared in the lab. Deuterated chloroform $\left(\mathrm{CDCl}_{3}\right)$ was obtained from Eurisotop. All other solvents were purchased from Carlo-Erba.

\section{Analytical methods}

Nuclear Magnetic Resonance Spectroscopy (NMR). NMR spectroscopy was performed in $5 \mathrm{~mm}$ diameter tubes in $\mathrm{CDCl}_{3}$ at $25{ }^{\circ} \mathrm{C} .{ }^{1} \mathrm{H}$ spectroscopy was performed on a Bruker Avance 300 spectrometer at $300 \mathrm{MHz}$. The chemical shift scale was calibrated on the basis of the internal solvent signals.

Size exclusion chromatography (SEC). SEC was performed at $30{ }^{\circ} \mathrm{C}$ with two columns from Polymer Laboratories (PL-gel MIXED-D; $300 \times 7.5 \mathrm{~mm}$; bead diameter, $5 \mu \mathrm{m}$; linear part, 400-400 000 g. $\mathrm{mol}^{-1}$ ) and a differential refractive index detector (Spectrasystem RI-150 from Thermo Electron Corp.), using chloroform as eluent, at a flow rate of $1 \mathrm{~mL} \cdot \mathrm{min}^{-1}$, and toluene as a flow-rate marker. The conventional calibration curve was based on polymer standards from Polymer Laboratories; either poly(methyl methacrylate) (PMMA) standards (peak molar masses, $M_{\mathrm{p}}=625-625500 \mathrm{~g} \cdot \mathrm{mol}^{-1}$ ) for all polymethacrylate copolymers or polystyrene (PS) standards $\left(M_{\mathrm{p}}=162-523000 \mathrm{~g} \cdot \mathrm{mol}^{-1}\right)$ for PLGA, PLA and PCL. This technique allowed $M_{\mathrm{n}}$ (number-average molar mass), $M_{\mathrm{w}}$ (weight-average molar mass), and $M_{\mathrm{w}} / M_{\mathrm{n}}$ (dispersity, $\left.Ð\right)$ to be determined.

Atomic force microscopy (AFM). AFM experiments were performed using the Nanowizard 3 Ultra Speed from JPK Instruments (Berlin, Germany, www.jpk.com), installed on an airbuffered table coupled to a dynamic anti-vibration device, and enclosed in an acoustic box. 
Imaging of the polymer thin film surface morphology was performed in air in $\mathrm{AC}$ or HyperDrive ${ }^{\circledR}$ mode, with gold-coated silicon cantilevers PPP-NCHAuD of $30 \pm 10 \mathrm{~N} . \mathrm{m}^{-1}$ spring constant and $290 \pm 5 \mathrm{kHz}$ resonance frequency (Nanosensors, Neuchatel, Switzerland). The pyramid-shaped tips had a radius of curvature less than $10 \mathrm{~nm}$. A free amplitude oscillation of $15 \mathrm{~nm}(1 \mathrm{~nm})$ was chosen in AC mode (in HyperDrive mode) allowing the best resolution of the imaged surface. In AC mode, setpoints ranging between $50 \%$ and $80 \%$ of the free amplitude were used depending on the polymer surface. Images were taken at scan rates of 1 or $2 \mathrm{~Hz}$. Image processing (flatten, plane fit, edge and hole detection) was performed with the JPK Data Processing software (JPK Instruments). At least three different areas of each sample were scanned and typical images were presented. Average values of height and lateral dimensions of surface features were determined with all pictures.

Scanning electron microscopy (SEM). Scanning Electron Microscopy (SEM) was performed using a MERLIN microscope (Carl Zeiss) and operating at $3 \mathrm{kV}$ with a filament current of about $0.5 \mathrm{~mA}$. Liquid samples were deposited on a carbon conductive double-sided tape (Euromedex, France). They were coated with a palladium-platinum layer of about $3 \mathrm{~nm}$ using a Cressington sputter-coater $208 \mathrm{HR}$ with a rotary-planetary-tilt stage, equipped with a MTM-20 thickness controller.

\section{Polymer synthesis}

Synthesis of poly[(methyl methacrylate)-co-(styrene)] (P(MMA-co-S), P1). In a $20 \mathrm{~mL}$ vial, fitted with a rubber septum and a magnetic bar, a mixture of MMA $\left(12.00 \mathrm{~g}, 1.20 \times 10^{-1}\right.$ $\mathrm{mol}), \mathrm{S}\left(1.235 \mathrm{~g}, 1.19 \times 10^{-2} \mathrm{~mol}\right)$ and the BlocBuilder MA alkoxyamine initiator $(0.084 \mathrm{~g}$, $\left.2.20 \times 10^{-4} \mathrm{~mol}\right)$ and free SG1 $\left(0.002 \mathrm{~g}, 5.85 \times 10^{-6} \mathrm{~mol}\right)$ was deoxygenated under stirring by nitrogen bubbling for $15 \mathrm{~min}$ at room temperature. The mixture was then immersed in a preheated oil bath at $90{ }^{\circ} \mathrm{C}$, corresponding to the time zero of the reaction. After $2 \mathrm{~h}$, the polymerization was stopped by cooling down to ambient temperature. The MMA conversion 
was calculated by ${ }^{1} \mathrm{H}$ NMR spectroscopy and the macromolecular characteristics of the copolymer $\left(M_{\mathrm{n}}\right.$ and $\left.Ð\right)$ were determined by SEC (using a calibration based on PMMA standards). The copolymer was then precipitated once in cold $\mathrm{MeOH}$ and dried under high vacuum until constant weight.

Synthesis of poly[(methyl methacrylate)-co-(2-methylene-4-phenyl-1,3-dioxolane) (P(MMA-co-MPDL), P2-P4). A typical solution copolymerization procedure (P2) is as follows. In a $40 \mathrm{~mL}$ vial, fitted with a rubber septum and a magnetic bar, a mixture of MMA $\left(12.100 \mathrm{~g}, 1.21 \times 10^{-1} \mathrm{~mol}\right)$, MPDL $\left(4.900 \mathrm{~g}, 3.02 \times 10^{-2} \mathrm{~mol}\right)$, the BlocBuilder MA alkoxyamine initiator $\left(0.061 \mathrm{~g}, 1.60 \times 10^{-4} \mathrm{~mol}\right)$ and anhydrous toluene $(17.0 \mathrm{~g}, 19.61 \mathrm{~mL})$ was deoxygenated under stirring by nitrogen bubbling for $15 \mathrm{~min}$ at room temperature. The mixture was then immersed in a preheated oil bath at $90{ }^{\circ} \mathrm{C}$, corresponding to the time zero of the reaction. After $8 \mathrm{~h}$, the polymerization was stopped by cooling down to ambient temperature. The MMA conversion was calculated by ${ }^{1} \mathrm{H}$ NMR spectroscopy and the macromolecular characteristics of the copolymer $\left(M_{\mathrm{n}}\right.$ and $\left.Ð\right)$ were determined by SEC (using a calibration based on PMMA standards). The copolymer was then precipitated once in cold $\mathrm{MeOH}$ and dried under high vacuum until constant weight. The same procedure was followed by adapting the amount of reactants for P3 [MMA $\left(8.652 \mathrm{~g}, 8.65 \times 10^{-2} \mathrm{~mol}\right)$, MPDL $(9.348$ $\left.\mathrm{g}, 5.77 \times 10^{-2} \mathrm{~mol}\right)$, BlocBuilder MA alkoxyamine initiator $\left.\left(0.0414 \mathrm{~g}, 1.09 \times 10^{-4} \mathrm{~mol}\right)\right]$ and P4 [MMA (3.766 g, $\left.3.77 \times 10^{-2} \mathrm{~mol}\right)$, MPDL (14.234 g, $\left.8.79 \times 10^{-2} \mathrm{~mol}\right)$, BlocBuilder MA alkoxyamine initiator $\left.\left(0.020 \mathrm{~g}, 5.35 \times 10^{-5} \mathrm{~mol}\right)\right]$. Final compositions of the copolymers were determined by comparing the methyl protons in $\alpha$-position to the ester group of MMA (at 3.7 $\mathrm{ppm}$ ) to the aromatic protons of MPDL (at $7.2 \mathrm{ppm}$ ).

Synthesis of poly[(oligo(ethylene glycol) methyl ether methacrylate)-co-(styrene)] (P(OEGMA-co-S), P5). In a $20 \mathrm{~mL}$ vial, fitted with a rubber septum and a magnetic bar, a mixture of OEGMA $\left(6.000 \mathrm{~g}, 2.00 \times 10^{-2} \mathrm{~mol}\right), \mathrm{S}\left(0.206 \mathrm{~g}, 1.98 \times 10^{-3} \mathrm{~mol}\right)$, the BlocBuilder 
MA alkoxyamine initiator $\left(0.024 \mathrm{~g}, 6.23 \times 10^{-5} \mathrm{~mol}\right)$ and free SG1 $\left(0.002 \mathrm{~g}, 5.85 \times 10^{-6} \mathrm{~mol}\right)$ was deoxygenated under stirring by nitrogen bubbling for $15 \mathrm{~min}$ at room temperature. The mixture was then immersed in a preheated oil bath at $90{ }^{\circ} \mathrm{C}$, corresponding to the time zero of the reaction. After $30 \mathrm{~min}$, polymerization was stopped by cooling down to ambient temperature. The OEGMA conversion was calculated by ${ }^{1} \mathrm{H}$ NMR spectroscopy and the macromolecular characteristics of the copolymer $\left(M_{\mathrm{n}}\right.$ and $\left.Ð\right)$ were determined by SEC (using a calibration based on PMMA standards). The copolymer was then precipitated once in a mixture of cold cyclohexane/petroleum ether $(1 / 1, \mathrm{v} / \mathrm{v})$ and dried under high vacuum until constant weight.

Synthesis of poly[(oligo(ethylene glycol) methyl ether methacrylate)-co-(2-methylene-4phenyl-1,3-dioxolane)] (P(OEGMA-co-MPDL), P6-P8). A typical solution copolymerization procedure (P6) is as follows. In a $20 \mathrm{~mL}$ vial, fitted with a rubber septum and a magnetic bar, a mixture of OEGMA (2.643 g, $\left.8.81 \times 10^{-3} \mathrm{~mol}\right)$, MPDL $(0.357 \mathrm{~g}, 2.20 \times$ $\left.10^{-3} \mathrm{~mol}\right)$, the BlocBuilder MA alkoxyamine initiator $\left(0.014 \mathrm{~g}, 3.78 \times 10^{-5} \mathrm{~mol}\right)$ and anhydrous toluene $(3.0 \mathrm{~g}, 3.46 \mathrm{~mL})$ was deoxygenated under stirring by nitrogen bubbling for $15 \mathrm{~min}$ at room temperature. The mixture was then immersed in a preheated oil bath at $90{ }^{\circ} \mathrm{C}$, corresponding to the time zero of the reaction. After $8 \mathrm{~h}$, the polymerization was stopped by cooling down to ambient temperature. The OEGMA conversion was calculated by ${ }^{1} \mathrm{H}$ NMR spectroscopy and the macromolecular characteristics of the copolymer $\left(M_{\mathrm{n}}\right.$ and $\left.Ð\right)$ were determined by SEC (using a calibration based on PMMA standards). The copolymer was then precipitated once in a mixture of cold cyclohexane/petroleum ether $(1 / 1, \mathrm{v} / \mathrm{v})$ and dried under high vacuum until constant weight. The same procedure was followed by adapting the amount of the reactants for P7 [OEGMA (2.206 g, $\left.7.35 \times 10^{-3} \mathrm{~mol}\right)$, MPDL $\left(0.794 \mathrm{~g}, 4.90 \times 10^{-3}\right.$ mol), BlocBuilder MA alkoxyamine initiator $\left(0.012 \mathrm{~g}, 3.10 \times 10^{-5} \mathrm{~mol}\right)$ ] and P8 [OEGMA $\left(1.328 \mathrm{~g}, 4.43 \times 10^{-3} \mathrm{~mol}\right), \operatorname{MPDL}\left(1.673 \mathrm{~g}, 1.03 \times 10^{-3} \mathrm{~mol}\right)$, BlocBuilder MA alkoxyamine 
initiator $\left.\left(0.0085 \mathrm{~g}, 2.20 \times 10^{-5} \mathrm{~mol}\right)\right]$. Final compositions of the copolymers were determined by comparing the terminal methoxy protons of OEG (at $3.4 \mathrm{ppm}$ ) to the ester group of MMA (at $3.7 \mathrm{ppm}$ ) to the aromatic protons of MPDL (at $7.2 \mathrm{ppm}$ ).

\section{Degradation experiments}

All the degradation experiments were performed in an orbital shaker (IKA KS4000i control) oven set at $150 \mathrm{rpm}$ and $37^{\circ} \mathrm{C}$.

Long-term hydrolytic degradation in PBS. $200 \mathrm{mg}$ of copolymer was poured into $20 \mathrm{~mL}$ of 0.1 M PBS and mechanically stirred in an orbital shaker thermostated at $37{ }^{\circ} \mathrm{C}$. Samples of 2 $\mathrm{mL}$ were withdrawn at different intervals (i.e., 4, 6 and 12 months) and lyophilized. $2 \mathrm{~mL}$ of chloroform were then added, allowing removal of buffer salts by filtration. Finally, the solvent was removed under reduced pressure and the degradation products were analyzed by SEC.

Hydrolytic degradation of thick polymer films. Films of $\sim 1 \mathrm{~mm}$ thickness, $150 \mathrm{mg}$ in mass and $1 \mathrm{~cm}^{2}$ surface area were prepared using a solvent casting method. The copolymer was solubilized in chloroform at a concentration of $200 \mathrm{mg} \cdot \mathrm{mL}^{-1} .0 .75 \mathrm{~mL}$ of copolymer solution was poured into plastic mold of $1 \mathrm{~cm}^{2}$. The mold was covered with aluminum foil and the solvent was slowly evaporated in air at room temperature for 3 days to prevent bubble formation. The resulting copolymer film was then further dried under high vacuum for one day to evaporate remaining solvent. After weighing, films were placed in individual vials containing $10 \mathrm{~mL}$ of $0.1 \mathrm{M}$ PBS and mechanically stirred in an orbital shaker thermostated at $37{ }^{\circ} \mathrm{C}$. Films were withdrawn at different intervals (i.e., 4, 6 and 12 months). Water uptake and mass loss were evaluated by weighing using the following equation: water uptake $=\frac{m_{w}-m_{d}}{m_{d}}$ where $m_{d}$ and $m_{w}$ are the mass of the dried film after degradation and the mass of the wet film after degradation (quickly wiped with paper), respectively and mass loss $=\frac{m_{d}-m_{0}}{m_{0}}$ where $\mathrm{m}_{0}$ is the initial mass. 
Hydrolytic degradation of thin polymer films. Thin films of $10 \mathrm{mg}$ in mass and $\sim 0.5 \mathrm{~cm}^{2}$ surface area were prepared using a solvent casting method. The copolymer was solubilized in chloroform, with a concentration of $200 \mathrm{mg} \cdot \mathrm{mL}^{-1} .50 \mu \mathrm{L}$ were dropped on a mica slide. The films were covered with aluminum foil and the solvent was evaporated slowly in air at room temperature for 2 days to prevent bubble formation. The resulting (co)polymer film was then annealed above the melting temperature of each (co)polymer; that is at $180{ }^{\circ} \mathrm{C}, 115^{\circ} \mathrm{C}$ and 80 ${ }^{\circ} \mathrm{C}$ for PMMA-based, PLA/PLGA and PCL films, respectively. When the annealing temperature was reached, thin films were dried under vacuum for $20 \mathrm{~h}$. Films were then placed in $10 \mathrm{~mL}$ of $0.1 \mathrm{M}$ PBS and mechanically stirred in an orbital shaker thermostated at $37{ }^{\circ} \mathrm{C}$. After selected intervals (i.e., 1, 6 and 12 months), films were withdrawn. Before imaging by SEM and AFM, they were washed with distilled water to remove salts that may be responsible for low image quality.

Enzymatic degradation. Copolymers were poured in $0.1 \mathrm{M}$ PBS at a concentration of 0.5 mg. $\mathrm{mL}^{-1}$ by the nanoprecipitation technique. $50 \mathrm{mg}$ of copolymer were solubilized in $2.5 \mathrm{~mL}$ of THF and added dropwise to $10 \mathrm{~mL}$ of $0.1 \mathrm{M}$ PBS. THF was evaporated and lipase from Candida Antartica (100 U.mL $\left.{ }^{-1}\right)$ was added to the mixture $(250 \mathrm{mg})$. After one week of incubation under stirring at $40{ }^{\circ} \mathrm{C}$, the mixture was lyophilized and $2 \mathrm{~mL}$ of chloroform were added allowing removal of buffer salts by filtration. The degradation products were then analyzed by SEC.

\section{Intravenous injections and preliminary toxicity to mice}

Female athymic nude mice (6-8 weeks old) were purchased from Harlan Laboratory. All animals were housed in appropriate animal care facilities during the experimental period and handled according to the principles of laboratory animal care and legislation in force in France (authorization No. 03803.02). Mice ( $20 \mathrm{~g})$ were randomly divided into 7 groups of 5 mice and each group received a single injection in the tail vein with either copolymers (P7 and P8) with concentrations from 0.8 to $2.4 \mathrm{~g} \cdot \mathrm{kg}^{-1}$ or $0.01 \mathrm{M}$ PBS as control. The injected 
volume was $10 \mu \mathrm{L}$ per gram of body weight. Mice were regularly monitored for changes in weight and behavior, and were humanely sacrificed 20 days after the injection.

\section{Results and Discussion}

\section{Synthesis and characterization of degradable copolymers}

Two libraries of degradable copolymers with $M_{\mathrm{n}}$ of $\sim 23000-35000$ g.mol ${ }^{-1}$ and comprising variable amounts of MPDL units were prepared by NMrROP. Copolymerizations between MPDL and MMA (P1-P4) or OEGMA (P5-P8) were initiated by the BlocBuilder alkoxyamine to yield either degradable hydrophobic or hydrophilic copolymers, respectively (Figure 3, Table 1). For both libraries, the initial molar fraction of MPDL, $f_{\mathrm{MPDL}, 0}$, was varied from 0.2 to 0.7 to adjust the amount of MPDL inserted in the copolymer and therefore its degree of degradation. Copolymers without MPDL were also synthesized by using styrene (S) as a 'controlling' comonomer, given the structural similarity of the styrenic radical with the open radical structure of MPDL (P1 and P5). 
(a)<smiles>CCOP(=O)(OCC)C(N(C(C)(C)C)C(C)(C)C)C(C)(C)C</smiles>

BlocBuilder<smiles>C=C(C)C(=O)OCCOC</smiles>

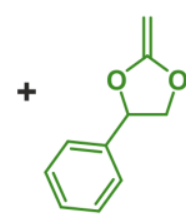

MPDL

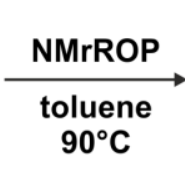

${ }^{\circ} \mathrm{C}$

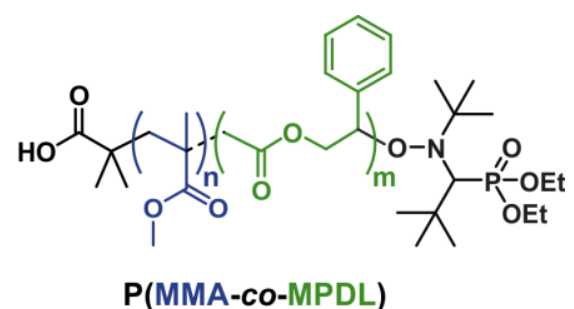

P2-P4

(b)<smiles>CCOC(=O)C(N(OC(C)(C)C)C(C)(C)C)C(C)(C)C</smiles>

BlocBuilder
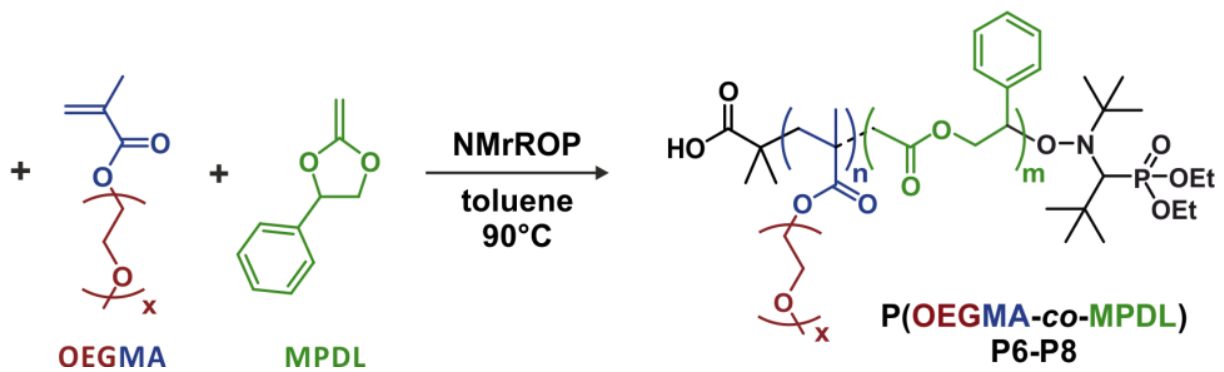

Figure 3. Synthesis of (a) poly[(methyl methacrylate)-co-(2-methylene-4-phenyl-1,3dioxolane)] (P(MMA-co-MPDL)) and (b) poly[(oligo(ethylene glycol) methyl ether methacrylate)-co-(2-methylene-4-phenyl-1,3-dioxolane)] (P(OEGMA-co-MPDL)) by nitroxide-mediated radical ring-opening copolymerization (NMrROP) of MMA (or OEGMA) and MPDL.

Table 1. Experimental Conditions and Macromolecular Characteristics of the Degradable Copolymers Used In This Study.

\begin{tabular}{ccccccc}
\hline Expt. & $\begin{array}{c}\text { Methacrylic } \\
\text { ester }\end{array}$ & $\boldsymbol{f}_{\text {MPDL,0 }}$ & $\begin{array}{c}\text { Conv. }^{\boldsymbol{a}}(\boldsymbol{\%}) / \\
\text { time (h) }\end{array}$ & $\begin{array}{c}\boldsymbol{M}_{\mathbf{n}}{ }^{\boldsymbol{b}} \\
(\mathbf{g} / \mathbf{m o l})\end{array}$ & $\boldsymbol{\Xi}^{\boldsymbol{b}}$ & $\boldsymbol{F}_{\text {MPDL }}{ }^{\boldsymbol{c}}$ \\
\hline $\mathbf{P 1}^{d}$ & MMA & 0 & $40 / 2.5$ & 32500 & 1.19 & 0 \\
$\mathbf{P 2}$ & MMA & 0.2 & $25 / 8$ & 30500 & 1.62 & 0.08 \\
$\mathbf{P 3}$ & MMA & 0.4 & $35 / 8$ & 32600 & 1.55 & 0.12 \\
$\mathbf{P 4}$ & MMA & 0.7 & $35 / 8$ & 35000 & 1.32 & 0.27 \\
\hline $\mathbf{P 5}^{d}$ & OEGMA & 0 & $29 / 0.5$ & 22900 & 1.24 & 0 \\
$\mathbf{P 6}$ & OEGMA & 0.2 & $42 / 8$ & 31600 & 1.35 & 0.09 \\
$\mathbf{P 7}$ & OEGMA & 0.4 & $46 / 8$ & 33100 & 1.32 & 0.15 \\
P8 & OEGMA & 0.7 & $36 / 8$ & 28300 & 1.19 & 0.27 \\
\hline
\end{tabular}

${ }^{a}$ Methacrylic ester conversion determined by ${ }^{1} \mathrm{H}$ NMR spectroscopy. ${ }^{b}$ Determined by SEC after purification from PMMA standards. ${ }^{c}$ Determined by ${ }^{1} \mathrm{H}$ NMR spectroscopy. ${ }^{d}$ Styrene was used as a controlling comonomer $\left(f_{\mathrm{S}, 0}=0.1\right)$.

Because MPDL acts as a 'controlling' comonomer during the NMP of methacrylic esters, the higher $f_{\text {MPDL, }, 0}$, the better the control of the copolymerization (Table 1). P(MMA-co-MPDL) 
copolymers exhibited decreasing dispersities from 1.62 to 1.32 by gradually increasing the initial amount of MPDL from 0.2 to 0.7. A similar trend was observed with P(OEGMA-coMPDL) copolymers whose dispersities ranged from 1.35 to 1.19 under identical experimental conditions.

The molar fraction of MPDL inserted in the copolymers was determined by ${ }^{1} \mathrm{H}$ NMR spectroscopy. Because of unfavorable reactivity ratios of MPDL/MMA $\left(r_{\mathrm{MPDL}}=0.01\right.$ and $\left.r_{\mathrm{MMA}}=4.0^{23}\right)$ and MPDL/OEGMA $\left(r_{\mathrm{MPDL}}=0\right.$ and $\left.r_{\mathrm{OEGMA}}=6.95^{24}\right)$ monomer pairs, the final amounts of MPDL in the copolymers, $F_{\text {MPDL }}$, were significantly lower that the initial amounts of MPDL in the comonomer feed. However, it was still possible to fine-tune $F_{\text {MPDL }}$ by $\operatorname{varying} f_{\mathrm{MPDL}, 0}$. It led, on average, to copolymers containing $~ 8 \%$ (P2 and P6), $14 \%$ (P3 and P7) and $\sim 27 \%$ (P4 and P8) for $f_{\text {MPDL }, 0}=0.2,0.4$ and 0.7, respectively (Table 1). As for control P(MMA-co-S) P1 and P(OEGMA-co-S) P5 copolymers without MPDL, they were nicely controlled with low dispersities (1.19 and 1.24, respectively).

\section{Long-term hydrolytic degradation in PBS}

Long-term hydrolytic degradation of the different copolymers was first investigated in PBS (0.1 M, pH 7.4) at $37{ }^{\circ} \mathrm{C}$ to mimic physiological conditions. All copolymers were poured in PBS and incubated under orbital-shaking at $150 \mathrm{rpm}$ and thermostated at $37^{\circ} \mathrm{C}$. MMA-based copolymers and traditional aliphatic polyesters were insoluble in water and thus dispersed in PBS whereas OEGMA-based copolymers were soluble in water (Figure S1). The evolution of the $M_{\mathrm{n}}$ was monitored by SEC for 12 months by withdrawing samples at different intervals (i.e., 4, 6 and 12 months).

Degradation of P(MMA-co-MPDL) was very slow and led to a decrease in $M_{\mathrm{n}}$ of $\sim 20$ $\%$ after 12 months (Figure 4a and S2). Conversely to our expectations, no effect of the MPDL content was noticed on the degradation. Despite constant stirring by orbital shaking, P(MMA- 
co-MPDL) copolymers poorly dispersed in water, leaving a persistent insoluble fraction at the water/air interface even after 12 months (Figure S1c). Conversely, P(OEGMA-co-MPDL) led to significant hydrolytic degradation under identical experimental conditions (Figure $4 \mathrm{~b}$ and S3). The decrease in $M_{\mathrm{n}}$ was governed by the MPDL fraction in the copolymer; the higher $F_{\text {MPDL }}$, the more significant the degradation. After 12 months, the $M_{\mathrm{n}}$ decrease reached -38, 55 and $-72 \%$ for $F_{\mathrm{MPDL}}=0.09,0.15$ and 0.27 , respectively.

The different degradation patterns of P(MMA-co-MPDL) and P(OEGMA-co-MPDL) copolymers can be explained by their different solubility in water. Whereas water-solubility of $\mathrm{P}(\mathrm{OEGMA}-\mathrm{co}-\mathrm{MPDL})$ is ensured by its $\mathrm{OEG}$ side chains, thus allowing water molecules to access to the ester groups in the main chain and cause degradation, $\mathrm{P}(\mathrm{MMA}-\mathrm{co}-\mathrm{MPDL})$ is too hydrophobic and exhibited poor water uptake that prevented significant degradation. This aspect will be further discussed in the Hydrolytic degradation of polymer films section. Both control copolymers P1 and P5 led to minimal degradation ( 14 \%) after 12 months, presumably because of partial hydrolysis of MMA and OEGMA units, respectively (note that such an artifact may also contribute to the decrease in $M_{\mathrm{n}}$ for copolymers P2-P4). Either hydrolysis is significant and the decrease in $M_{\mathrm{n}}$ is caused by loss of multiple methyl or OEG groups, or it is marginal but the few resulting carboxylic acid groups lead to interaction with SEC columns, thus affecting the retention time. ${ }^{28}$ This last hypothesis seems predominant since ${ }^{1} \mathrm{H}$ NMR spectra of P(MMA-co-MPDL) and P(OEGMA-co-MPDL) did not show any noticeable change of integration for the peaks of the methyl/methylene protons in the $\alpha$ position to the ester bond. 
(a)

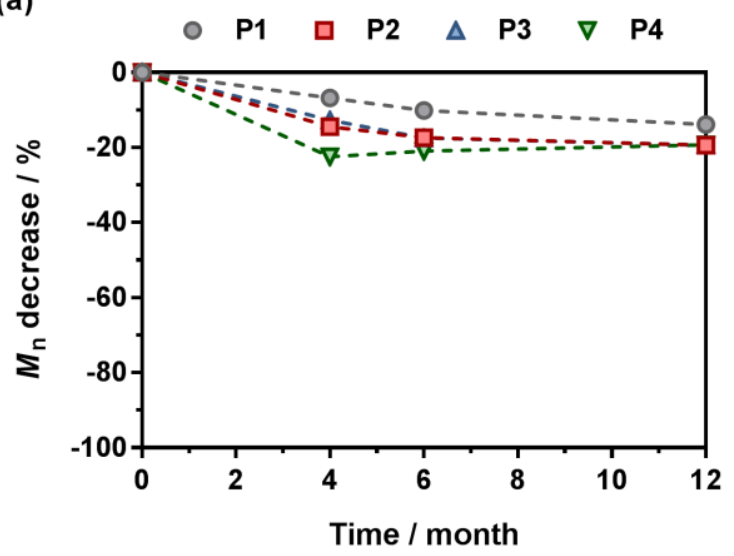

(c)

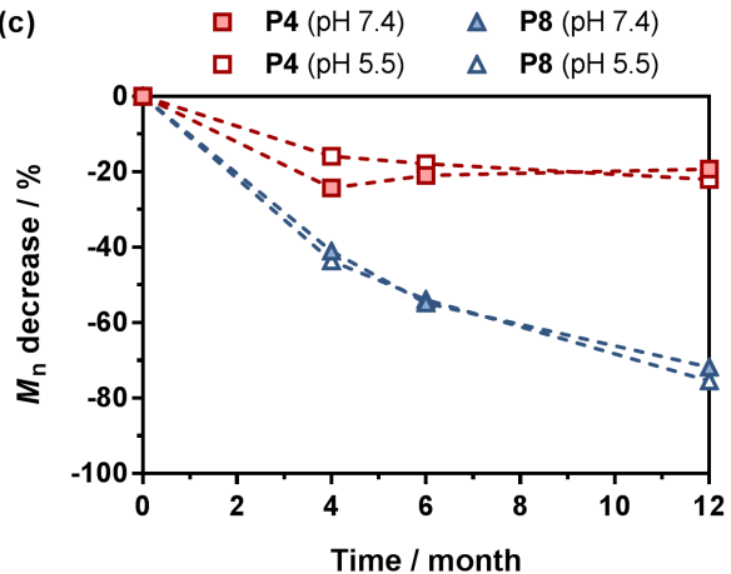

(b)

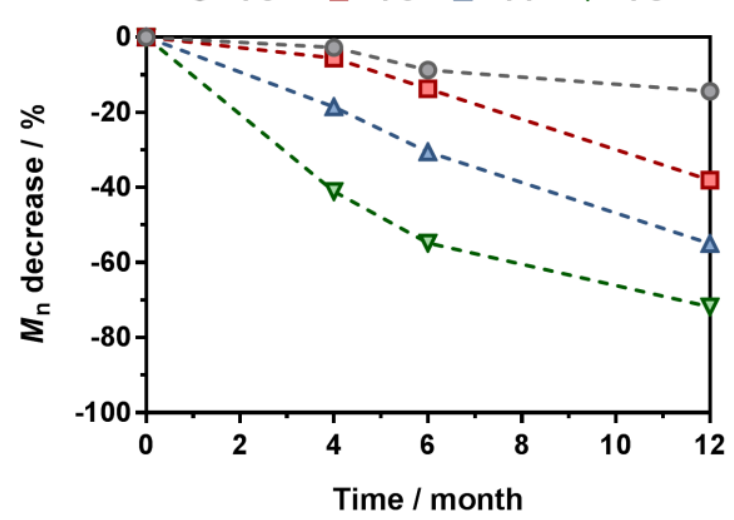

(d)

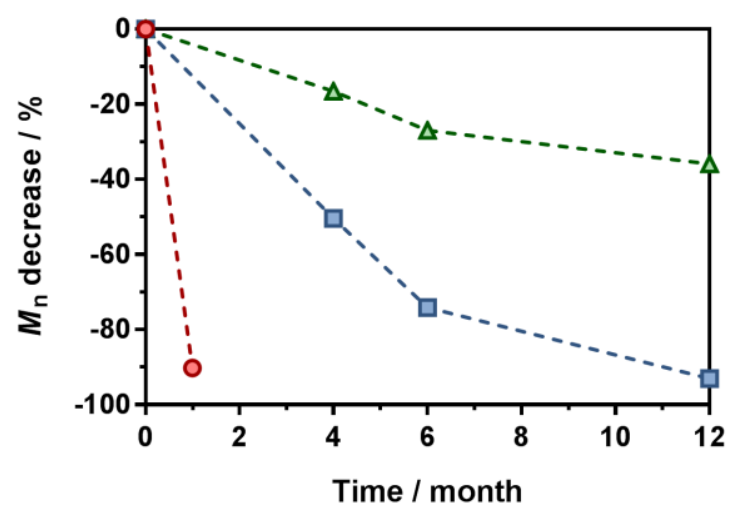

Figure 4. Evolution of the number-average molar mass, $M_{\mathrm{n}}$, with time of the different copolymers during the hydrolytic degradation in $\mathrm{PBS}\left(0.1 \mathrm{M}, \mathrm{pH} 7.4,37^{\circ} \mathrm{C}\right)$. (a) $\mathrm{P}(\mathrm{MMA}-\mathrm{co}-$ MPDL $): \mathbf{P 1}\left(F_{\mathrm{MPDL}}=0\right) ; \mathbf{P 2}\left(F_{\mathrm{MPDL}}=0.08\right) ; \mathbf{P 3}\left(F_{\mathrm{MPDL}}=0.12\right) ; \mathbf{P 4}\left(F_{\mathrm{MPDL}}=0.27\right)$. (b) P(OEGMA-co-MPDL): P5 $\left(F_{\mathrm{MPDL}}=0\right) ; \mathbf{P 6}\left(F_{\mathrm{MPDL}}=0.09\right) ; \mathbf{P 7}\left(F_{\mathrm{MPDL}}=0.15\right) ; \mathbf{P 8}\left(F_{\mathrm{MPDL}}=\right.$ 0.27). (c) Influence of the $\mathrm{pH}: \mathbf{P 4}$ (pH 7.4 or 5.5); $\mathbf{P 8}$ (pH 7.4 or 5.5). (d) Aliphatic polyesters $(\mathrm{pH} 7.4)$.

Evolution with time of the $M_{\mathrm{n}}$ of P(OEGMA-co-MPDL), and in particular of the slope of the curves, suggested that even though hydrolytic degradation did not reach completion after 12 months, lower $M_{\mathrm{n}}$ will likely be obtained if the degradation is prolonged for a longer period of time (Figure $4 \mathrm{~b}$ ). However, the final theoretical $M_{\mathrm{n}}$ after complete degradation can be estimated from the final composition of the copolymers, providing nearly statistical incorporation of MPDL all along the copolymer chain. Given the unfavorable reactivity ratio of MPDL (MPDL/OEGMA: $r_{\mathrm{MPDL}}=0$ and $r_{\mathrm{OEGMA}}=6.95 ;{ }^{24} \mathrm{MPDL} / \mathrm{MMA}: r_{\mathrm{MPDL}}=0.1$ and 
$\left.r_{\mathrm{MMA}}=4\right),{ }^{23}$ it was assumed that the number of consecutive MPDL units was negligible. Thus, the average number of OEGMA units between two MPDL units was calculated according to $1 / F_{\mathrm{MPDL}}-1$ and was equal to 10,6 and 3 for $F_{\mathrm{MPDL}}=0.09(\mathbf{P 6}), 0.15(\mathbf{P 7})$ and $0.27(\mathbf{P 8})$, respectively. It would correspond to a residual $M_{\mathrm{n}}$ of 3200 (P6), $1900(\mathbf{P 7})$ and 1000 g.mol ${ }^{-1}$ (P8) and a final $M_{\mathrm{n}}$ decrease of 90, 94 and 96\%, respectively.

Influence of $\mathrm{pH}$ on degradation was then investigated. One copolymer from each library, $\mathbf{P 4}$ and P8, was subjected to degradation in acetate buffer ( $\mathrm{pH}$ 5.5) for 12 months and the degradation pattern was compared to that obtained in PBS (0.1 M, pH 7.4). However, no noticeable effect was observed on the degradation rate as shown by a nearly perfect overlay of $M_{\mathrm{n}}$ values at each time point (Figure $4 \mathrm{c}$ ).

A key aspect of the study was whether our materials could be competitive in terms of degradation under physiological conditions, with traditional aliphatic polyesters. The two series of MPDL-containing copolymers were therefore benchmarked with PLGA, PLA and PCL. Identical degradation conditions (PBS, $0.1 \mathrm{M}$, pH 7.4) were applied and evolution of $M_{\mathrm{n}}$ after different periods of time was reported on Figure 4d and S4. As previously reported, degradation of PLGA was the fastest, leading to complete degradation after 1 month. ${ }^{29}$ As expected, since PLA is more sterically hindered than PLGA, its complete degradation took a longer time, approximately 12 months, ${ }^{30}$ whereas degradation of PCL was the slowest leading to a decrease in $M_{\mathrm{n}}$ of only $36 \%$ after 12 months. ${ }^{31}$ As for our MPDL-containing copolymers, P(MMA-co-MPDL) P2-P4 exhibited slightly slower degradation rates than that of PCL. However, hydrolytic degradation of P(OEGMA-co-MPDL) P6-P8 was comprised between that of PLA and PCL. It is a very important result showing that hydrolytic degradation of properly designed CKA-containing vinyl copolymers can be in the same order of magnitude than degradation of PCL and PLA, which are extensively used FDA-approved biodegradable polymers. 
$\mathrm{pH}$ was monitored over time during hydrolytic degradation at $\mathrm{pH} 7.4$ of OEGMAbased copolymers P5-P8, and of PLGA, PLA and PCL (Figure 5). Hydrolytic degradation of polyester leads to carboxylic acid chain-end frequently associated with a drop in $\mathrm{pH}^{32,33} \mathrm{pH}$ of PLGA and PLA dispersions decreased from 7.4 to 5.5 after 1 and 12 months, respectively. ${ }^{32,33}$ This drop in $\mathrm{pH}$ may be a strong limitation as it was shown that local acidification produced by the degradation products of PLGA/PLA usually resulted in detrimental local inflammatory response. ${ }^{32,33}$ Because of the minimal degradation of PCL over this period of time, no drop in $\mathrm{pH}$ was observed. Remarkably, $\mathrm{pH}$ of the different $\mathrm{P}(\mathrm{OEGMA}-\mathrm{co}-\mathrm{MPDL})$ solutions was stable and remain $>6.8$ even after 1 year, as for $\mathrm{P}(\mathrm{OEGMA}-\mathrm{co}-\mathrm{S})$ used as a control copolymer. This high $\mathrm{pH}$ stability, related to a lower number of carboxylic acid moieties released from MPDL-containing copolymers during the degradation process, is very relevant and represents a meaningful advantage compared to aliphatic polyesters as their in vivo degradation may not lead to local acidification and probably to local toxicity.

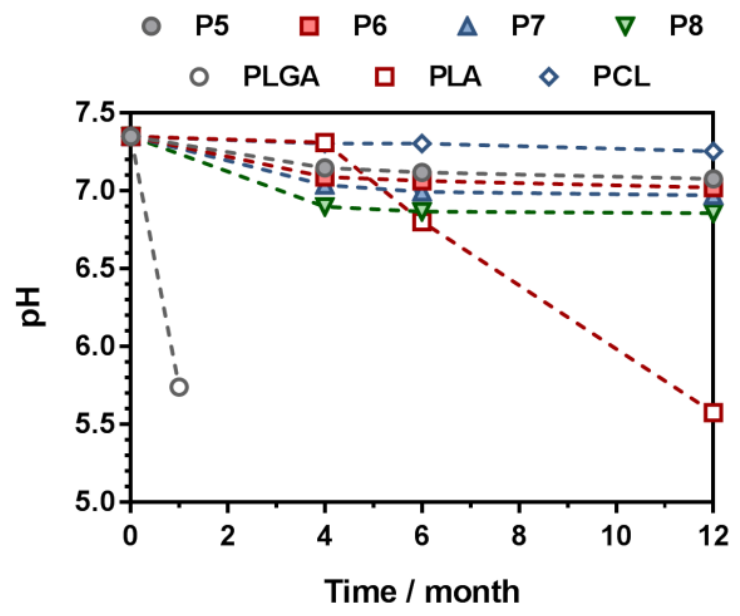

Figure 5. Evolution of $\mathrm{pH}$ with time during hydrolytic degradation in $\mathrm{PBS}(0.1 \mathrm{M}$, pH 7.4, $\left.37^{\circ} \mathrm{C}\right)$ of OEGMA-based copolymers: $\bullet, \mathbf{P 5}\left(F_{\mathrm{MPDL}}=0\right)$; $\mathbf{\square}, \mathbf{P 6}\left(F_{\mathrm{MPDL}}=0.09\right) ; \boldsymbol{\Delta}, \mathbf{P 7}\left(F_{\mathrm{MPDL}}\right.$ $=0.15) ; \boldsymbol{\nabla}, \mathbf{P 8}\left(F_{\mathrm{MPDL}}=0.27\right)$ and aliphatic polyesters. 


\section{Hydrolytic degradation of polymer films}

Films of approximatively $150 \mathrm{mg}$ in mass, $1 \mathrm{~mm}$ thickness and $1 \mathrm{~cm}^{2}$ surface area (Figure S5) were prepared by the solvent casting method from hydrophobic (co)polymers: $\mathrm{P}(\mathrm{MMA}-\mathrm{co}-\mathrm{S})$ P1, P(MMA-co-MPDL) P2-P4, PLA, PLGA, and PCL. Hydrolytic degradation was carried out in PBS (0.1 M, pH 7.4) stirred in an orbital shaker thermostated at $37{ }^{\circ} \mathrm{C}$. Erosion of hydrophobic polymers occurs through surface or bulk erosion ${ }^{34,35}$ and the balance between the kinetics of diffusion of water inside the polymer matrix and the hydrolysis rate of the polymer's labile groups defines the erosion mechanism. If water diffusion is faster than the labile group hydrolysis, the material degrades through bulk erosion. On the contrary, if the chain cleavage is faster than water diffusion, the material undergoes surface erosion. Water uptake and mass loss were monitored for 12 months. In parallel, thin films ( 10 mg in mass, $0.5 \mathrm{~cm}^{2}$ surface area) were prepared on mica surface for further scanning electron microscopy (SEM) and atomic force microscopy (AFM) observations to gain some insight into the degradation mechanism of our copolymers.

The water uptake ability of thick polymer films was first determined by comparing their weight in wet and dry states (Figure 6a). Water uptake of PLGA and PLA films was fast and reached values as high as $\sim 210 \%$ after 1 month for PLGA and $\sim 500 \%$ after 4 months for PLA. This behavior confirmed that water significantly diffused inside PLGA/PLA matrix, in agreement with their relatively fast degradation rates (Figure 4d). PCL and P(MMA-coMPDL) P2-P4 films gave less than $8 \%$ of water uptake. These results were consistent with long-term hydrolytic degradation experiments that showed very slow degradation of dispersed PCL and P(MMA-co-MPDL) copolymers.

Although the strong hydrophobicity of P(MMA-co-MPDL) copolymers may explain their poor water uptake, influence of their glass transition temperature (i.e., segmental mobility) cannot be ruled out. $T_{\mathrm{g}} \mathrm{s}$ of PLGA and PLA are about $44-48{ }^{\circ} \mathrm{C}$ and $48-52{ }^{\circ} \mathrm{C}$, respectively, ${ }^{36}$ so relatively close to the experimental temperature $\left(37^{\circ} \mathrm{C}\right)$. Therefore, 
although glassy, polymer chains still have some segmental flexibility, favoring water penetration in the polymer matrix. ${ }^{37}$ For PCL, the situation was more complicated. Even if its $T_{\mathrm{g}}\left(-60^{\circ} \mathrm{C}\right)$ is significantly lower than the experimental temperature, the crystallinity of the polymer strongly hampered water uptake. ${ }^{38}$ Conversely, $T_{\mathrm{g}}$ of $\mathrm{P}(\mathrm{MMA}-\mathrm{co}-\mathrm{MPDL})$ is equal to $107{ }^{\circ} \mathrm{C}$ for $\mathbf{P 1}, 100{ }^{\circ} \mathrm{C}$ for $\mathbf{P 2}, 98^{\circ} \mathrm{C}$ for $\mathbf{P 3}$ and $74{ }^{\circ} \mathrm{C}$ for $\mathbf{P 4},{ }^{23}$ so much higher than those of PLGA and PLA. Consequently, not only P(MMA-co-MPDL) copolymers were hydrophobic but also very rigid and highly compact, thus preventing water molecules to extensively diffuse into the polymer matrix to induce degradation. ${ }^{37,39}$
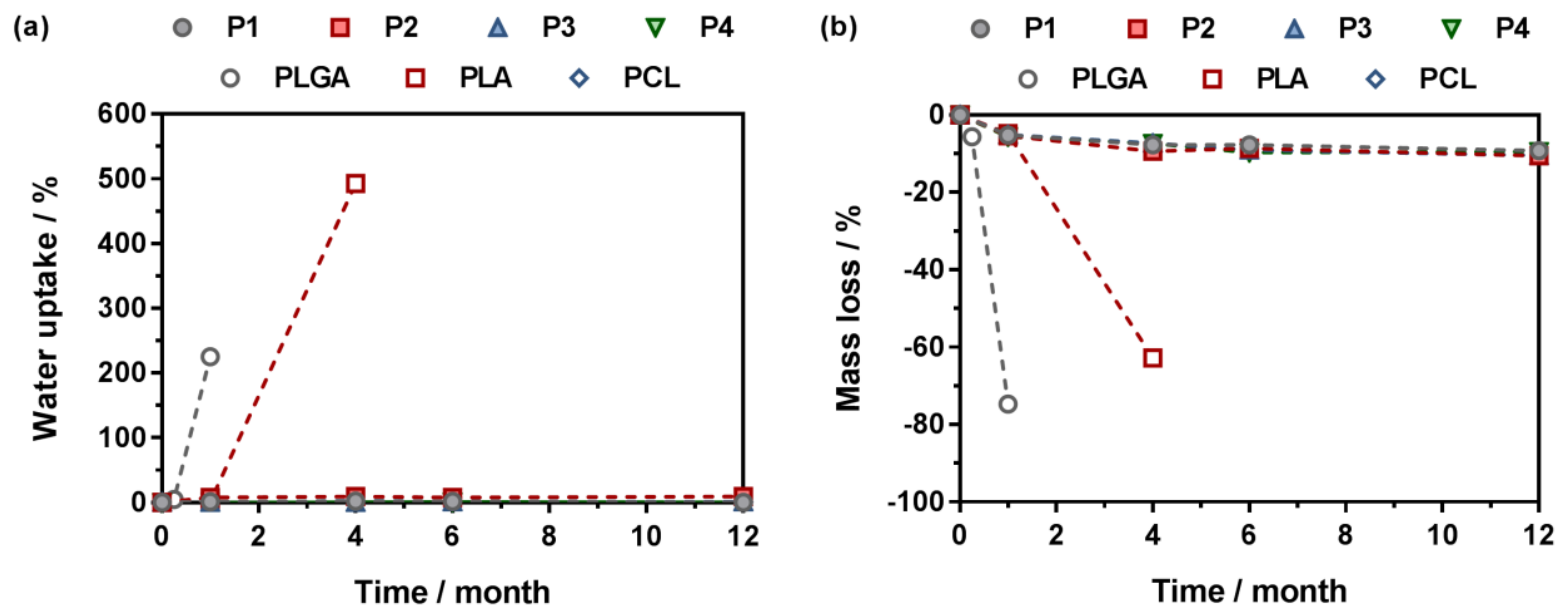

Figure 6. (a) Water uptake and (b) mass loss of thick films during hydrolytic degradation in PBS $\left(0.1 \mathrm{M}, \mathrm{pH} 7.4,37^{\circ} \mathrm{C}\right)$ of MMA-based copolymers: $\bullet, \mathbf{P 1}\left(F_{\mathrm{MPDL}}=0\right)$;, $\mathbf{P 2}\left(F_{\mathrm{MPDL}}=\right.$ $0.08) ; \boldsymbol{\Delta}, \mathbf{P 3}\left(F_{\mathrm{MPDL}}=0.12\right) ; \boldsymbol{\nabla}, \mathbf{P 4}\left(F_{\mathrm{MPDL}}=0.27\right)$ and aliphatic polyesters.

Similarly to water uptake, mass loss of PLGA and PLA thick films in 0.1 M PBS under identical degradation conditions was fast (Figure 6b). PLGA films lost $\sim 75 \%$ of their mass after 1 month and PLA lost $\sim 63 \%$ after 4 months. In contrast, MMA-based copolymers P2P4 and PCL had similar behavior, with a mass loss around $10 \%$ after 12 months (note that copolymer P1 lost mass to the same extent as MPDL-containing copolymers, which might be assign to partial hydrolysis of MMA units). As water hardly entered into the polymer matrix, 
only the surface of film was likely subjected to degradation, which left the bulk intact. Photographs of P(MMA-co-MPDL) P4, PLGA, PLA and PCL films before and after 12, 1, 4 and 12 months in $0.1 \mathrm{M}$ PBS, respectively, further illustrated the rapid degradation of PLGA and PLA films as opposed to the nearly hydrolytic stability of films from P4 and PCL (Figure S5). These data supported that P(MMA-co-MPDL) and PCL films ${ }^{38}$ were degraded through a surface erosion mechanism.

SEM (Figure 7) and AFM (height images in Figure 8, cross section in Figure S6 and phase images in Figure S7) were then used to gain insight into surface erosion of thin polymer films from P(MMA-co-S) P1, P(MMA-co-MPDL) P2-P4, PLGA, PLA and PCL. Note that all thin film surfaces before hydrolysis (0 month) were not perfectly smooth at the nanometric scale and exhibited either several clusters of a few tens of nanometers high or roughness of the same range. Importantly, as the degree of hydrolysis reached an advanced stage (6 or 12 months), all films underwent drastic changes in their surface morphology with increased roughness or with the apparition of pores. The apparition of a tip effect on pictures was characteristic of degraded surface and meant that transfer of matter from the degraded surface to the AFM tip occurred during imaging. This matter modified the tip geometry and resulted in altered resolution in AFM imaging.

PLGA thin films were totally degraded after 1 month. SEM images showed highly porous micrometric cavities. This micrometric roughness added to a softening of the material prevented us from obtaining AFM pictures of PLGA film surface. For PLA film, erosion was slower and SEM pictures showed a PLA film surface of increasing porosity with time. Several micrometric holes were formed after 1-month hydrolysis, reaching tens of micrometers after 12 months. However, these porous structures were less visible by AFM. After 6 months, surface became rougher and small holes appeared, whereas after 12 months, the morphology of the surface drastically changed and large cavities of $30 \mathrm{~nm}$ deep appeared. For PCL, SEM 
pictures showed numerous holes after 1 month which were turned into large and porous cavities after 12 months. By AFM, the surface of the film before hydrolysis was rough, with a difference in height of $50 \mathrm{~nm}$. After 1 month, the surface seemed to flatten and for the 6months hydrolysis, larger holes with a depth of $100 \mathrm{~nm}$ appeared. The 12 months film was too rough and porous to be observed by AFM with good resolution.

As expected, P(MMA-co-S) P1 did not show drastic modification of morphology. By AFM, clusters seemed to erode with time, although this was less obvious by SEM. AFM observation of the copolymer with the lowest MPDL content $\left(\mathbf{P 2}, F_{\mathrm{MPDL}}=0.08\right)$ showed a surface becoming more rugged and the clusters disappeared after 1 month. After 6 months, porosity started with a depth of 10 to $20 \mathrm{~nm}$ and after 12 months, holes became more numerous and their size and deep increased. The AFM pictures after 12 months of hydrolysis showed a drastic change in morphology, associated with advanced hydrolysis of the material. SEM images confirmed the apparition of numerous small holes on the surface of the films. For MPDL molar fraction of 0.12 (P3), the material became porous (20 to $40 \mathrm{~nm}$ deep) within only 1 month and the size and number of pores increased with time. The modification in morphology characteristic of film erosion was observed by AFM after 12 months. By SEM, many small holes similar to those observed by AFM were observed and bigger cavities of few micrometers appeared after 6 months. For the highest MPDL content $\left(\mathbf{P 4}, F_{\mathrm{MPDL}}=0.27\right)$, several holes appeared on the surface after one month and the change in morphology occurred after only 6 months. After 12 months, large (few hundreds of nm) and deep (few tens nm) holes were observed on the surface by SEM. One can note that in all cases, AFM phase imaging pointed out the softening of the material with time (Figure S6), which became more viscoelastic while hydrolysis proceeded.

Altogether, these data indicated that films composed of P(MMA-co-MPDL) undergo surface erosion, similarly to PCL films. Because of the strong hydrophobicity and rigidity of 
the copolymers, water uptake was rather modest $(<10 \%)$, thus preventing bulk hydrolysis. Although slow, surface erosion was confirmed by both AFM and SEM and the kinetic of porosity formation on the surface of the film was affected by the MPDL content: the higher the MPDL content, the earlier the holes formation. 

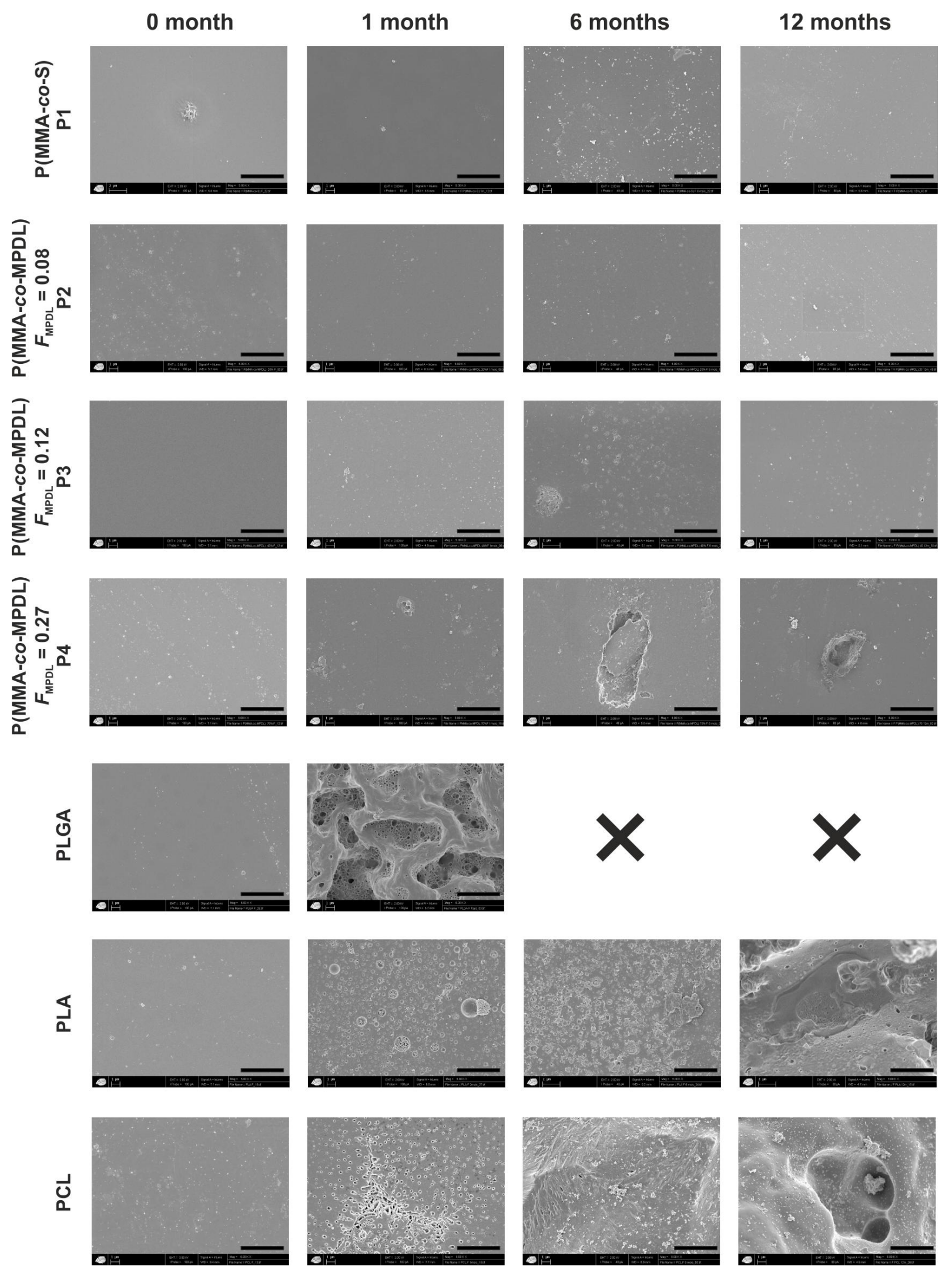

Figure 7. SEM images $(\mathrm{Mag}=5 \mathrm{KX})$ showing the evolution of thin film surfaces of MMAbased copolymers P1-P4, PLGA, PLA and PCL during hydrolytic degradation in PBS (0.1 $\left.\mathrm{M}, \mathrm{pH} 7.4,37^{\circ} \mathrm{C}\right)$. Scale bar $=5 \mu \mathrm{m}$. 


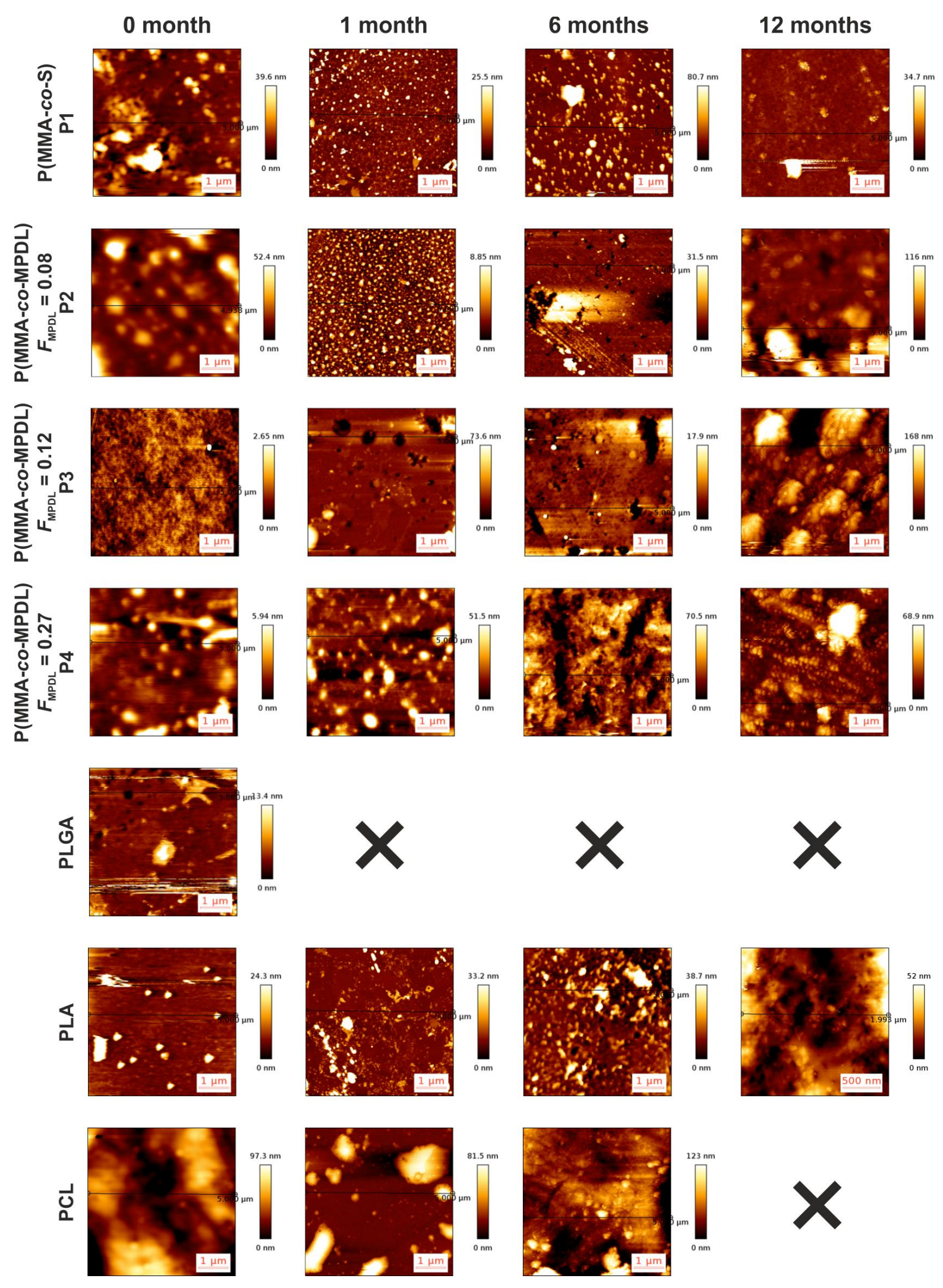

Figure 8. AFM height images obtained in AC mode during hydrolytic degradation in PBS (0.1 M, pH 7.4, $\left.37^{\circ} \mathrm{C}\right)$ of MMA-based copolymers P1-P4, PLGA, PLA and PCL $(5 \mu \mathrm{m} \times 5$ $\mu \mathrm{m}$, except for PLA at 12 months, $2 \mu \mathrm{m} \times 2 \mu \mathrm{m}$ ). The z-scale is indicated on the right side of each image (colored bar). 


\section{Enzymatic degradation}

Hydrolytic degradation is of utmost importance while considering polyester family, as it is considered to be the main degradation mechanism in vivo. ${ }^{40}$ However, since they are also susceptible to enzymatic degradation, ${ }^{41}$ the sensitivity of $\mathrm{P}(\mathrm{MMA}-\mathrm{co}-\mathrm{MPDL})$ and $\mathrm{P}(\mathrm{OEGMA}-\mathrm{co}-\mathrm{MPDL})$ copolymers to the action of lipases, a sub-class of the esterases, was studied. Incubation of the different copolymers was performed in $0.1 \mathrm{M}$ PBS at $37{ }^{\circ} \mathrm{C}$ for one week in presence of lipases from Candida Antartica, one enzyme already used in the literature for such a purpose. ${ }^{16,27,42}$ Enzymatic cleavage is known to be specific and to catalyze hydrolysis, enzymes need to interact with their substrate (i.e., the ester bond of the polymer). ${ }^{43-45}$ Consequently, the affinity between the polymer main chain and the enzyme as well as the environment of the ester bond strongly affect the efficacy of the enzyme.

Negligible degradation was observed with P(MMA-co-MPDL) copolymers (P1-P4, Table 2), as illustrated by nearly perfect overlay of the SEC chromatograms all along the experiment (Figure S8). Conversely, P(OEGMA-co-MPDL) (P4-P8) displayed moderate degradation (-6-15\%) while the control copolymer without MPDL (P5) was perfectly inert (Table 2, Figure S9).

Table 2. Evolution Of The Number-Average Molar Mass $\left(M_{\mathrm{n}}\right)$ Of P(MMA-co-MPDL) and P(OEGMA-co-MPDL) Copolymers After Enzymatic Degradation.

\begin{tabular}{cccc}
\hline Expt. & Methacrylic ester & $\begin{array}{c}\boldsymbol{F}_{\text {MPDL }}{ }^{\boldsymbol{1}} \\
(\mathbf{m o l} \mathbf{\%})\end{array}$ & $\begin{array}{c}\boldsymbol{M}_{\mathbf{n}} \text { decrease }^{\boldsymbol{b}} \\
(\boldsymbol{\%})\end{array}$ \\
\hline P1 & MMA & 0 & -2 \\
P2 & MMA & 8 & -3 \\
P3 & MMA & 12 & -2 \\
P4 & MMA & 27 & -1 \\
\hline P5 & OEGMA & 0 & $<-1$ \\
P6 & OEGMA & 9 & -15 \\
P7 & OEGMA & 15 & -13 \\
P8 & OEGMA & 27 & -6 \\
\hline
\end{tabular}

${ }^{a}$ Determined by ${ }^{1} \mathrm{H}$ NMR spectroscopy. ${ }^{b}$ Determined by SEC using PMMA standards. 
We assumed that hydrophobicity of the P(MMA-co-MPDL) copolymer backbone prevented interaction between the enzyme active site and ester functions, whereas the relatively watersolubility of P(OEGMA-co-MPDL) copolymers enabled at least partial enzymatic cleavage. However, we suspected the detrimental influence of hydrophobic MPDL units on enzyme accessibility to ester moieties as the higher the MPDL content in the copolymer, the lower the $M_{\mathrm{n}}$ decrease: $-15 \%$ for P6 $\left(F_{\mathrm{MPDL}}=0.09\right),-13 \%$ for $\mathbf{P 7}\left(F_{\mathrm{MPDL}}=0.15\right)$ and $-6 \%$ for $\mathbf{P 8}$ $\left(F_{\mathrm{MPDL}}=0.27\right)$. This trend should however be taken with care given the error of measurement from SEC. In addition, high aromatic group contents may result in interaction between aromatic rings ( $\pi$-stacking) from MPDL units and induce specific conformation of the polymer chains, ${ }^{4,46}$ that would further reduce accessibility to ester functions. Also, given PEG is known to induce steric repulsion of proteins, one can question, even though they are relatively small, the adverse effect of OEG side chains on enzyme accessibility to the ester groups. Although enzymatic degradation was modest, it could likely be improved as it has been shown that performing the degradation on a longer timescale (35 days) and replacing the degradation medium every $24 \mathrm{~h}$ enabled extensive degradation of MPDL-containing materials. $^{47}$

\section{Preliminary in vivo toxicity}

Although OEGMA-based materials are considered to be non-toxic and potentially stealth, ${ }^{16,48-}$ ${ }^{57}$ inserting multiple MPDL units group could modify the toxicity of the resulting copolymers. Even though innocuousness of $\mathrm{P}(\mathrm{OEGMA}-\mathrm{co}-\mathrm{MPDL})$ copolymers was previously demonstrated on two representative mammalian cell types, ${ }^{24}$ in vivo toxicity has never been investigated.

P(OEGMA-co-MPDL) copolymers containing 15 and $27 \%$ MPDL (P7 and P8, respectively) were injected intravenously (single injection) in mice with concentrations 
ranging from 0.8 to $2.4 \mathrm{~g} \cdot \mathrm{kg}^{-1}$. The body weight and the mice behavior were monitored for 20 days. In all cases, despite a slight weight decrease during the first 6 days (ranging from -0.5 to $-5 \%$ ), in general for the highest copolymer concentrations, evolution of body weight was nearly constant with time, similarly to untreated mice (Figure 9). Except for P8 at $0.8 \mathrm{mg} \cdot \mathrm{kg}^{-1}$, the higher the copolymer concentration, the higher the body weight loss. However, neither mortality nor noticeable modification in terms of feeding and behavior was observed, suggesting the safety of the treatment.

(a)

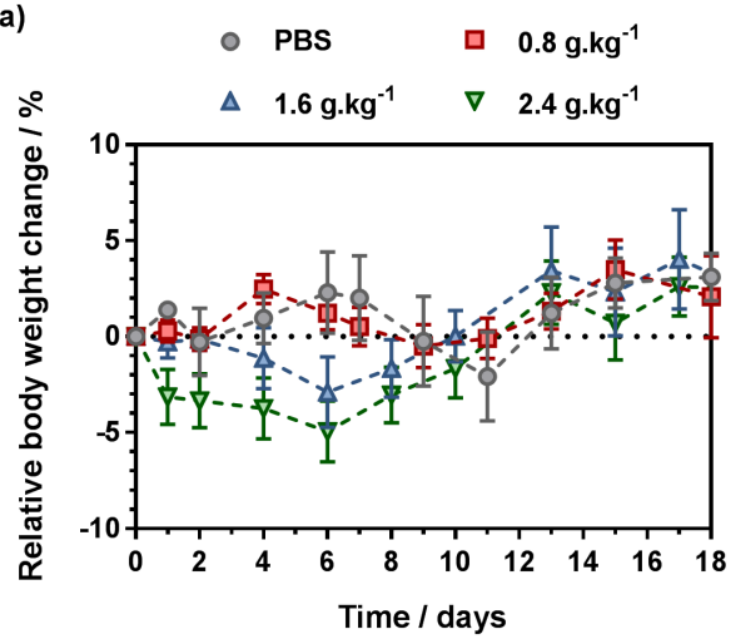

(b)

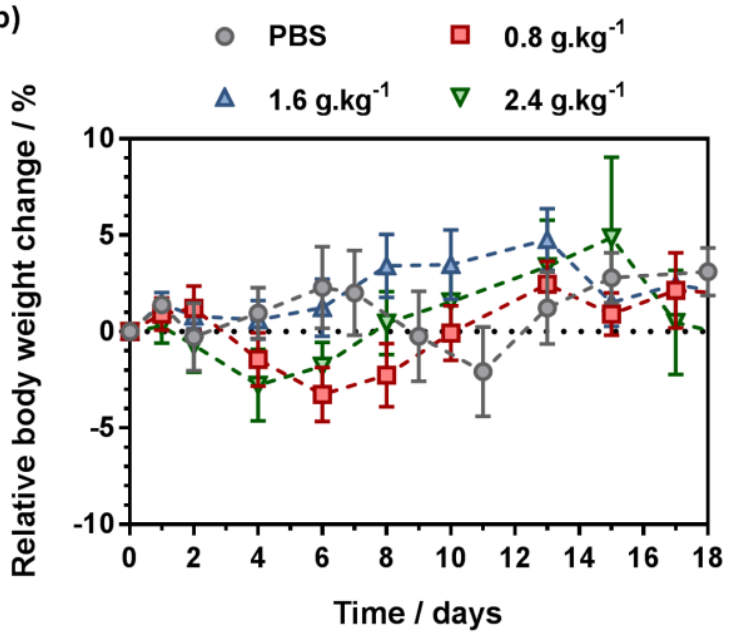

Figure 9. Relative body weight change of mice, as a function of time after intravenous injections of PBS (0.01 M) or P(OEGMA-co-MPDL) (a) P7 and (b) P8. The error bars represent the standard deviation $(\mathrm{SD}, \mathrm{n}=5)$.

Interestingly, the median lethal dose $\left(\mathrm{LD}_{50}\right)$ of traditional hydrophobic polyesters was equal to 0.22 g. $\mathrm{kg}^{-1}$ for PLGA nanoparticles ${ }^{58}$ and 1.47 g.kg ${ }^{-1}$ for PEG- $b$-PCL nanoparticles ${ }^{59}$ and PEGb-PLA nanoparticles were well tolerated up to $0.44 \mathrm{~g} \cdot \mathrm{kg}^{-1} \cdot{ }^{60}$ Despite the fact that P(OEGMAco-MPDL) copolymers are water-soluble and not under the form of nanoparticles, their innocuousness in vivo, even at high concentration (2.4 g. $\left.\mathrm{kg}^{-1}\right)$, makes them promising building block for the design of biocompatible and biodegradable polymers. Also, in vivo 
toxicity of non-degradable, hydrophilic polymers, such as PEG, was also weak and $\mathrm{LD}_{50}$ ranged from $8.6 \mathrm{~g} \cdot \mathrm{kg}^{-1}$ for $M_{\mathrm{n}}, \mathrm{PEG}=400 \mathrm{~g} \cdot \mathrm{mol}^{-1}$ to $16.0 \mathrm{~g} \cdot \mathrm{kg}^{-1}$ for $M_{\mathrm{n}}, \mathrm{PEG}=4000 \mathrm{~g} \cdot \mathrm{mol}^{-1} \cdot{ }^{61,62}$

\section{Conclusion}

Comprehensive degradation study of well-defined MPDL-containing polymethacrylates copolymers of opposite solubility (either based on MMA or OEGMA) synthesized by NMrROP, by means of long-term hydrolytic degradation, degradation of thick and thin films together with enzymatic degradation, all achieved in PBS $\left(0.1 \mathrm{M}, \mathrm{pH} 7.4,37^{\circ} \mathrm{C}\right)$, was performed and point-by-point comparison with traditional aliphatic polyesters (PLGA, PLA and PCL) was established for benchmarking purposes.

It was shown that P(MMA-co-MPDL) copolymers slowly degraded in PBS with degradation kinetics slower than that of PCL. P(MMA-co-MPDL) film erosion suggested that combination of copolymer hydrophobicity and rigidity prevented bulk erosion and thus a slow surface erosion was observed by SEM and AFM. As expected, no decrease in $M_{\mathrm{n}}$ was obtained after enzymatic degradation.

Conversely, water-soluble $\mathrm{P}(\mathrm{OEGMA}-\mathrm{co}-\mathrm{MPDL})$ copolymers led to significant degradation under long term hydrolysis in PBS. The degradation kinetics was finely tuned by varying the MPDL content, which enabled to obtain degradation performances in between those of PLA and PCL, thus representing an important result. However, P(OEGMA-coMPDL) copolymers were only moderately degraded by enzymes, likely because of a combination between a too high hydrophobicity of MPDL units, potential conformation of the copolymer chain because of hydrophobic interaction and steric repulsion of OEG side chains, thus preventing optimal cleavage by the enzyme. 
On one hand, as they remained rather stable under hydrolytic and enzymatic conditions, $\mathrm{P}(\mathrm{MMA}-\mathrm{co}$-MPDL) copolymers might be well-suited for biomaterials intended for long-term use, such as devices or implants. ${ }^{7,46,63,64}$ On the other hand, P(OEGMA-coMPDL) demonstrated promising degradation rate under hydrolytic conditions and might thus be envisioned for short- or mid-term applications such as nanoscale drug-delivery systems and meet a need for hydrophilic degradable materials with tunable degradation kinetics.

\section{Acknowledgments}

We thank the French Ministry of Research for the financial support of the PhD thesis of EG. Arkema is warmly acknowledged for kindly providing the BlocBuilder MA alkoxyamine and the SG1 nitroxide. The CNRS is also acknowledged for financial support. The authors also thank L. Moine (Institut Galien Paris-Sud, Châtenay-Malabry) for fruitful discussions and R. Pirres (ICMPE, Thiais) for SEM experiments.

\section{Supporting Information}

Pictures of the copolymer solutions or dispersion in PBS during hydrolytic degradation, evolution of the SEC chromatograms of MPDL-containing copolymers and polyesters during hydrolytic and enzymatic degradations, pictures of the polymer films during hydrolytic degradation, AFM cross sections and phase images during hydrolytic degradation.

\section{References}

1. Gross, R. A.; Kalra, B. Biodegradable Polymers for the Environment. Science 2002, 297, 803-807.

2. Siracusa, V.; Rocculi, P.; Romani, S.; Dalla Rosa, M. Biodegradable Polymers for Food Packaging: A Review. Trends Food Sci. Technol. 2008, 19, 634-643. 
3. Tian, H.; Tang, Z.; Zhuang, X.; Chen, X.; Jing, X. Biodegradable Synthetic Polymers: Preparation, Functionalization and Biomedical Application. Prog. Polym. Sci. 2012, 37 , 237-280.

4. Frazza, E.; Schmitt, E. A New Absorbable Suture. J. Biomed. Mater. Res., Part A 1971, $5,43-58$.

5. Nair, L. S.; Laurencin, C. T. Biodegradable Polymers as Biomaterials. Prog. Polym. Sci. 2007, 32, 762-798.

6. Anderson, J. M.; Shive, M. S. Biodegradation and Biocompatibility of Pla and Plga Microspheres. Adv. Drug Delivery Rev. 2012, 64, 72-82.

7. Ulery, B. D.; Nair, L. S.; Laurencin, C. T. Biomedical Applications of Biodegradable Polymers. J. Polym. Sci., Part B: Polym. Phys. 2011, 49, 832-864.

8. Tardy, A.; Delplace, V.; Siri, D.; Lefay, C.; Harrisson, S.; Pereira, B. d. F. A.; Charles, L.; Gigmes, D.; Nicolas, J.; Guillaneuf, Y. Scope and Limitations of the NitroxideMediated Radical Ring-Opening Polymerization of Cyclic Ketene Acetals. Polym. Chem. 2013, 4, 4776-4787.

9. Matyjaszewski, K.; Xia, J. Atom Transfer Radical Polymerization. Chem. Rev. 2001, 101, 2921-2990.

10. Moad, G.; Rizzardo, E.; Thang, S. H. Living Radical Polymerization by the Raft Process-a Second Update. Aust. J. Chem. 2009, 62, 1402-1472.

11. Delplace, V.; Nicolas, J. Degradable Vinyl Polymers for Biomedical Applications. Nature Chem. 2015, 7, 771-784.

12. Tardy, A.; Nicolas, J.; Gigmes, D.; Lefay, C.; Guillaneuf, Y. Radical Ring-Opening Polymerization: Scope, Limitations, and Application to (Bio) Degradable Materials. Chem. Rev. 2017, 117, 1319-1406.

13. Bailey, W. J.; Ni, Z.; Wu, S. R. Synthesis of Poly-€-Caprolactone Via a Free Radical Mechanism. Free Radical Ring-Opening Polymerization of 2-Methylene-1, 3-Dioxepane. J. Polym. Sci., Part A: Polym. Chem. 1982, 20, 3021-3030.

14. Bailey, W. J.; Ni, Z.; Wu, S. R. Free Radical Ring-Opening Polymerization of 4, 7Dimethyl-2-Methylene-1, 3-Dioxepane and 5, 6-Benzo-2-Methylene-1, 3-Dioxepane. Macromolecules 1982, 15, 711-714.

15. Chung, I. S.; Matyjaszewski, K. Synthesis of Degradable Poly (Methyl Methacrylate) Via Atrp: Atom Transfer Radical Ring-Opening Copolymerization of 5-Methylene-2Phenyl-1, 3-Dioxolan-4-One and Methyl Methacrylate. Macromolecules 2003, 36, 2995-2998.

16. Lutz, J.-F.; Andrieu, J.; Üzgün, S.; Rudolph, C.; Agarwal, S. Biocompatible, Thermoresponsive, and Biodegradable: Simple Preparation of "All-in-One" Biorelevant Polymers. Macromolecules 2007, 40, 8540-8543.

17. Agarwal, S.; Ren, L. Polycaprolactone-Based Novel Degradable Ionomers by Radical Ring-Opening Polymerization of 2-Methylene-1, 3-Dioxepane. Macromolecules 2009, 42, 1574-1579.

18. Kobben, S.; Ethirajan, A.; Junkers, T. Synthesis of Degradable Poly (Methyl Methacrylate) Star Polymers Via Raft Copolymerization with Cyclic Ketene Acetals. $J$. Polym. Sci., Part A: Polym. Chem. 2014, 52, 1633-1641. 
19. Huang, J.; Gil, R.; Matyjaszewski, K. Synthesis and Characterization of Copolymers of 5, 6-Benzo-2-Methylene-1, 3-Dioxepane and N-Butyl Acrylate. Polymer 2005, 46, 11698-11706.

20. Hedir, G. G.; Bell, C. A.; Ieong, N. S.; Chapman, E.; Collins, I. R.; O’Reilly, R. K.; Dove, A. P. Functional Degradable Polymers by Xanthate-Mediated Polymerization. Macromolecules 2014, 47, 2847-2852.

21. Ganda, S.; Jiang, Y.; Thomas, D. S.; Eliezar, J.; Stenzel, M. H. Biodegradable Glycopolymeric Micelles Obtained by Raft-Controlled Radical Ring-Opening Polymerization. Macromolecules 2016, 49, 4136-4146.

22. d'Ayala, G. G.; Malinconico, M.; Laurienzo, P.; Tardy, A.; Guillaneuf, Y.; Lansalot, M.; D'Agosto, F.; Charleux, B. Raft/Madix Copolymerization of Vinyl Acetate and 5, 6-Benzo-2-Methylene-1, 3-Dioxepane. J. Polym. Sci., Part A: Polym. Chem. 2014, 52, 104-111.

23. Tran, J.; Guegain, E.; Ibrahim, N.; Harrisson, S.; Nicolas, J. Efficient Synthesis of 2Methylene-4-Phenyl-1, 3-Dioxolane, a Cyclic Ketene Acetal for Controlling the Nmp of Methyl Methacrylate and Conferring Tunable Degradability. Polym. Chem. 2016, 7, 4427-4435.

24. Delplace, V.; Guégain, E.; Harrisson, S.; Gigmes, D.; Guillaneuf, Y.; Nicolas, J. A Ring to Rule Them All: A Cyclic Ketene Acetal Comonomer Controls the NitroxideMediated Polymerization of Methacrylates and Confers Tunable Degradability. Chem. Commun. 2015, 51, 12847-12850.

25. Jin, Q.; Maji, S.; Agarwal, S. Novel Amphiphilic, Biodegradable, Biocompatible, Cross-Linkable Copolymers: Synthesis, Characterization and Drug Delivery Applications. Polym. Chem. 2012, 3, 2785-2793.

26. Sun, L. F.; Zhuo, R. X.; Liu, Z. L. Synthesis and Enzymatic Degradation of 2Methylene-1,3-Dioxepane and Methyl Acrylate Copolymers. J. Polym. Sci., Part A: Polym. Chem. 2003, 41, 2898-2904.

27. Undin, J.; Illanes, T.; Finne-Wistrand, A.; Albertsson, A.-C. Random Introduction of Degradable Linkages into Functional Vinyl Polymers by Radical Ring-Opening Polymerization, Tailored for Soft Tissue Engineering. Polym. Chem. 2012, 3, 12601266.

28. Specht, C. H.; Frimmel, F. H. Specific Interactions of Organic Substances in SizeExclusion Chromatography. Environ. Sci. Technol. 2000, 34, 2361-2366.

29. Zolnik, B. S.; Burgess, D. J. Effect of Acidic Ph on Plga Microsphere Degradation and Release. J. Control. Rel. 2007, 122, 338-344.

30. Tsuji, H.; Ikarashi, K. In Vitro Hydrolysis of Poly (L-Lactide) Crystalline Residues as Extended-Chain Crystallites. Part I: Long-Term Hydrolysis in Phosphate-Buffered Solution at 37 C. Biomaterials 2004, 25, 5449-5455.

31. Castilla-Cortázar, I.; Más-Estellés, J.; Meseguer-Dueñas, J.; Ivirico, J. E.; Marí, B.; Vidaurre, A. Hydrolytic and Enzymatic Degradation of a Poly (E-Caprolactone) Network. Polym. Degrad. Stab. 2012, 97, 1241-1248.

32. Taylor, M.; Daniels, A.; Andriano, K.; Heller, J. Six Bioabsorbable Polymers: In Vitro Acute Toxicity of Accumulated Degradation Products. J. Appl. Biomater. 1994, 5, 151157. 
33. Ignatius, A.; Claes, L. E. In Vitro Biocompatibility of Bioresorbable Polymers: Poly (L, Dl-Lactide) and Poly (L-Lactide-Co-Glycolide). Biomaterials 1996, 17, 831-839.

34. Göpferich, A. Mechanisms of Polymer Degradation and Erosion. Biomaterials 1996, 17, 103-114.

35. von Burkersroda, F.; Schedl, L.; Göpferich, A. Why Degradable Polymers Undergo Surface Erosion or Bulk Erosion. Biomaterials 2002, 23, 4221-4231.

36. data provided by Sigma Aldrich

37. Breitenbach, A.; Pistel, K.; Kissel, T. Biodegradable Comb Polyesters. Part Ii. Erosion and Release Properties of Poly (Vinyl Alcohol)-G-Poly (Lactic-Co-Glycolic Acid). Polymer 2000, 41, 4781-4792.

38. Lam, C. X.; Hutmacher, D. W.; Schantz, J. T.; Woodruff, M. A.; Teoh, S. H. Evaluation of Polycaprolactone Scaffold Degradation for 6 Months in Vitro and in Vivo. J. Biomed. Mater. Res., Part A 2009, 90, 906-919.

39. Dušková-Smrčková, M.; Dušek, K. Processes and States During Polymer Film Formation by Simultaneous Crosslinking and Solvent Evaporation. J. Mater. Sci. 2002, 37, 4733-4741.

40. Vert, M.; Li, S.; Spenlehauer, G.; Guérin, P. Bioresorbability and Biocompatibility of Aliphatic Polyesters. J. Mater. Sci.: Mater. Med. 1992, 3, 432-446.

41. Tokiwa, Y.; Calabia, B. P. Biodegradability and Biodegradation of Polyesters. J. Polym. Environ. 2007, 15, 259-267.

42. He, F.; Li, S.; Vert, M.; Zhuo, R. Enzyme-Catalyzed Polymerization and Degradation of Copolymers Prepared from $\epsilon$-Caprolactone and Poly (Ethylene Glycol). Polymer 2003, 44, 5145-5151.

43. Liederer, B. M.; Borchardt, R. T. Enzymes Involved in the Bioconversion of Ester-Based Prodrugs. J. Pharm. Sci. 2006, 95, 1177-1195.

44. Fersht, A. Catalysis, Binding and Enzyme-Substrate Complementarity. Proc. R. Soc. Lond., B Biol. Sci. 1974, 187, 397-407.

45. Lienhard, G. E. Enzymatic Catalysis and Transition-State Theory. Science 1973, 180, 149-154.

46. Yao, D.; Smith, A.; Nagarajan, P.; Vasquez, A.; Dang, L.; Chaudhry, G. R. Fabrication of Polycaprolactone Scaffolds Using a Sacrificial Compression-Molding Process. $J$. Biomed. Mater. Res., Part B 2006, 77, 287-295.

47. Zhang, Y.; Zheng, M.; Kissel, T.; Agarwal, S. Design and Biophysical Characterization of Bioresponsive Degradable Poly (Dimethylaminoethyl Methacrylate) Based Polymers for in Vitro DNA Transfection. Biomacromolecules 2012, 13, 313-322.

48. Ozer, I.; Tomak, A.; Zareie, H. M.; Baran, Y.; Bulmus, V. Effect of Molecular Architecture on Cell Interactions and Stealth Properties of Peg. Biomacromolecules 2017, 18, 2699-2710.

49. Chenal, M.; Mura, S.; Marchal, C.; Gigmes, D.; Charleux, B.; Fattal, E.; Couvreur, P.; Nicolas, J. Facile Synthesis of Innocuous Comb-Shaped Polymethacrylates with Peg Side Chains by Nitroxide-Mediated Radical Polymerization in Hydroalcoholic Solutions. Macromolecules 2010, 43, 9291-9303. 
50. Chenal, M.; Boursier, C.; Guillaneuf, Y.; Taverna, M.; Couvreur, P.; Nicolas, J. First Peptide/Protein Pegylation with Functional Polymers Designed by Nitroxide-Mediated Polymerization. Polym. Chem. 2011, 2, 1523-1530.

51. Louguet, S.; Verret, V.; Bédouet, L.; Servais, E.; Pascale, F.; Wassef, M.; Labarre, D.; Laurent, A.; Moine, L. Poly (Ethylene Glycol) Methacrylate Hydrolyzable Microspheres for Transient Vascular Embolization. Acta Biomater. 2014, 10, 11941205.

52. Bontempo, D.; Maynard, H. D. Streptavidin as a Macroinitiator for Polymerization: In Situ Protein- Polymer Conjugate Formation. J. Am. Chem. Soc. 2005, 127, 6508-6509.

53. Pasut, G.; Veronese, F. M. Peg Conjugates in Clinical Development or Use as Anticancer Agents: An Overview. Adv. Drug Delivery Rev. 2009, 61, 1177-1188.

54. Lutz, J. F. Polymerization of Oligo (Ethylene Glycol)(Meth) Acrylates: Toward New Generations of Smart Biocompatible Materials. J. Polym. Sci., Part A: Polym. Chem. 2008, 46, 3459-3470.

55. Ryan, S. M.; Mantovani, G.; Wang, X.; Haddleton, D. M.; Brayden, D. J. Advances in Pegylation of Important Biotech Molecules: Delivery Aspects. Expert Opin. Drug Deliv. 2008, 5, 371-383.

56. Harris, J. M.; Chess, R. B. Effect of Pegylation on Pharmaceuticals. Nat. Rev. Drug Discov. 2003, 2, 214-222.

57. Jokerst, J. V.; Lobovkina, T.; Zare, R. N.; Gambhir, S. S. Nanoparticle Pegylation for Imaging and Therapy. Nanomedicine 2011, 6, 715-728.

58. Kopčanský, P.; Tomašovičová, N.; Koneracka, M.; Timko, M.; Závišová, V.; Tomčo, L. Magnetic Nanoparticles in Magnetic Fluids. Acta Electrotechnica et Informatica 2010, 10, 10-13.

59. Kim, S. Y.; Lee, Y. M.; Baik, D. J.; Kang, J. S. Toxic Characteristics of Methoxy Poly (Ethylene Glycol)/Poly (E-Caprolactone) Nanospheres; in Vitro and in Vivo Studies in the Normal Mice. Biomaterials 2003, 24, 55-63.

60. Plard, J.-P.; Bazile, D. Comparison of the Safety Profiles of Pla 50 and Me. Peg-Pla 50 Nanoparticles after Single Dose Intravenous Administration to Rat. Colloids Surf., B 1999, 16, 173-183.

61. Rowe, R.; Sheskey, P.; Quinn, M., Handbook of Pharmaceutical Excipients. Pharmaceutical Press: London, England, 2009; p 637.

62. Smyth, H. F.; Carpenter, C. P.; Weil, C. S. The Toxicology of the Polyethylene Glycols. J. Pharm. Sci. 1950, 39, 349-354.

63. Middleton, J. C.; Tipton, A. J. Synthetic Biodegradable Polymers as Orthopedic Devices. Biomaterials 2000, 21, 2335-2346.

64. Sabir, M. I.; Xu, X.; Li, L. A Review on Biodegradable Polymeric Materials for Bone Tissue Engineering Applications. J. Mater. Sci. 2009, 44, 5713-5724. 